\title{
Polygonisation of railway wheels: a critical review
}

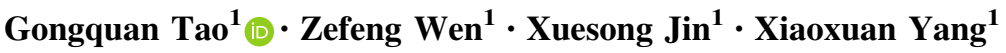

Received: 17 April 2020/Revised: 7 September 2020/Accepted: 9 September 2020/Published online: 29 September 2020

(C) The Author(s) 2020

\begin{abstract}
Polygonisation is a common nonuniform wear phenomenon occurring in railway vehicle wheels and has a severe impact on the vehicle-track system, ride comfort, and lineside residents. This paper first summarizes periodic defects of the wheels, including wheel polygonisation and wheel corrugation, occurring in railways worldwide. Thereafter, the effects of wheel polygonisation on the wheel-rail interaction, noise and vibration, and fatigue failure of the vehicle and track components are reviewed. Based on the different causes, the formation mechanisms of periodic wheel defects are classified into three categories: (1) initial defects of wheels, (2) natural vibration of the vehicle-track system, and (3) thermoelastic instability. In addition, the simulation methods of wheel polygonisation evolution and countermeasures to mitigate wheel polygonisation are presented. Emphasis is given to the characteristics, effects, causes, and solutions of wheel polygonisation in metro vehicles, locomotives, and highspeed trains in China. Finally, the guidance is provided on further understanding the formation mechanisms, monitoring technology, and maintenance criterion of wheel polygonisation.
\end{abstract}

Keywords Railway vehicle - Wheel polygonisation - Wear mechanism $\cdot$ Wheel-rail interaction

Zefeng Wen

zfwen@home.swjtu.edu.cn

1 State Key Laboratory of Traction Power, Southwest Jiaotong University, Chengdu 610031, China

\section{Introduction}

Railway vehicles rely on wheel-rail rolling contact for operation. Wheel out-of-roundness (OOR), especially wheel polygonisation, strongly influences the operational safety and quality of railway vehicles. Shortly after the ICE1 high-speed train was put into operation in Germany, a polygonisation phenomenon was observed to occur on the wheel tread, causing noise in the frequency range of $70-100 \mathrm{~Hz}$ and also resulting in medium-frequency structural vibration of the car body. To reduce the wheel-rail rolling noise and vehicle structure vibration, solid wheels were replaced by rubber-sprung ones. However, fatigue failure of a rubber-sprung wheel caused a derailment accident in Eschede, Germany, in 1998 [1]. The results of the accident investigation showed that the rubber wheels exhibited polygonisation with two harmonics around the wheel circumference. This can lead to a violently fluctuating wheel-rail contact load, and the wheel rim may fracture under alternating loads.

Wheel OOR is one of the major challenges in the field of wheel-rail interaction and can cause wheel-rail impact vibration, and wheel-rail rolling and impact noise, thereby significantly reducing the vehicle ride comfort. The shock and vibration caused by wheel OOR can be transmitted to the vehicle and track, causing fatigue failure of the vehicle and track components [2]. Wheel OOR is also a key parameter that affects the wheel-rail dynamic loads and causes ground-borne vibration [3]. In the late 1990s, many researchers began to study the wheel OOR phenomenon. With the rapid development of high-speed railways and urban rail transit in China, the topic of wheel OOR or polygonal wear has often appeared in the railway transportation field. Wheel polygonisation is a hot topic in China and has attracted increasing attention from railway 
researchers and engineers. Many Chinese researchers have begun conducting research on wheel polygonal wear, and most scientific papers on wheel polygonal wear in the past decade have been published by Chinese scholars.

Several reviews have been published in the past. Nielsen and Johansson [4] presented a review on wheel OOR in 2000 that focused on classifying the wheel OOR, summarizing the causes of each type of wheel OOR, impact load detection, methods for numerical simulation of the causes of wheel OOR, removal criteria of OOR wheels (mainly wheel flat), and prediction of wheel OOR evolution. Nielsen et al. [5] summarized the causes of wheel corrugation and low-order polygonal wear and mitigation measures in 2003. Barke and Chui [2] reviewed the effect of wheel OOR on vehicle and track components in 2005. Many new studies on wheel polygonisation have emerged in the last decade. The objective of this literature survey is to describe the state-of-the-art research on wheel polygonisation. In Sect. 2, periodic wheel defects occurring in railways, including wheel polygonisation and wheel corrugation, are discussed. The effect of wheel polygonisation on the wheel-rail interaction, noise and vibration, and fatigue reliability of the vehicle and track components is presented in Sect. 3. The formation mechanism of wheel polygonisation proposed by researchers is summarized and classified in Sect. 4. The simulation of wheel polygonisation evolution and countermeasures against wheel polygonisation are described in Sects. 5 and 6, respectively. Finally, a summary and outlook for future work on wheel polygonisation are provided in Sect. 7.

\section{Summary of periodic wheel defects in railway field}

Wheel polygonisation and wheel corrugation are the two main types of periodic wheel defects. Generally, wheel polygonisation has a periodic irregularity around the wheel circumference superimposed on a constant wheel radius. The wavelength of the irregularity ranges from $14 \mathrm{~cm}$ to approximately the circumference of one wheel, whereas the amplitude is approximately $1 \mathrm{~mm}$ [4]. This defect was detected only on disc-braked wheelsets before 2000 . Wheel corrugation mainly appears on block-braked wheelsets. The wavelength of this defect is $30-60 \mathrm{~mm}$, and the amplitude is less than $10 \mu \mathrm{m}$ [4].

Similar to rail corrugation, the periodic wheel defects often occur in railway field. Generally, rail corrugation forms easily on sharp curves, especially in urban rail transit systems. The present authors' research team has been investigating more than 30 metro lines in China and has measured both wheel OOR and rail corrugation. Rail corrugation occurs in almost every line, whereas wheel polygonal wear or wheel corrugation only appears in six metro lines (except for eccentricity). Compared with rail corrugation, the periodic wheel defect often has a greater influence on vehicles. As the periodic wheel defect is not as common as rail corrugation, there has been less research activity on periodic wheel defects than on rail corrugation.

Polygonal or corrugated wear has been found on locomotive, freight train, metro train, and high-speed train wheels. According to Zacher [6], the wheels of ICE trains in Germany exhibited first-, third-, and fourth-harmonic wear. Pallgen et al. [7] concluded that the third- and second-order OOR defects were dominant on standard solid steel wheels and rubber-sprung wheels, respectively. The Vancouver mass-transit system suffered from serious wheel corrugation within six months after opening [8]. Dings and Dittrich [9] indicated that the wheels with castiron block brakes on the Dutch railway showed obvious corrugation with a dominant wavelength of $50-70 \mathrm{~mm}$. In Ref. [5], it was reported that approximately $60 \%$ of the measured wheels on one line in the Stockholm subway network suffered from polygonal wear with three harmonics. Wheel corrugation, with dominant wavelengths of $30-80 \mathrm{~mm}$, was detected on high-speed X2 railway wheels of powered vehicle in Sweden [10]. Recently, wheel polygonal wear has been reported on the next-generation locomotive TRAXX in Switzerland [11] and freight locomotive in South Africa [12]. Typical measurement results of the periodic wheel defects are shown in Fig. 1.

Field investigation of wheel polygonisation in China began in 2008 and was conducted by the authors' research team. Over the past 12 years, our research team has investigated the problem of wheel polygonal wear in China. Our past research mainly focused on metro trains, high-speed trains, and locomotives. According to our field investigations, the linear-induction-motor (LIM) metro trains in two lines exhibited wheel polygonal wear with nine harmonics [13], which is the first reported case of wheel polygonal wear in China. After that, another four metro lines suffering from wheel polygonal wear were reported by our research team, such as $5-8$ harmonics around the wheel circumference exhibiting on the type-B metro train with a maximum operating speed of $80 \mathrm{~km} / \mathrm{h}$ [14], 11-16 harmonics occurring on the type-A metro train with a maximum operating speed of $80 \mathrm{~km} / \mathrm{h}$ [15], and 12-14 harmonics appearing on the type-B metro train with a maximum operating speed of $120 \mathrm{~km} / \mathrm{h}$ [16]. The typical polygonal wear measurement results of the metro train wheels investigated by the authors' research team are shown in Fig. 2. Figure 3 shows a photograph of wheel corrugation with a wavelength of approximately $30 \mathrm{~mm}$ on a type-B metro train with a maximum operating speed of $80 \mathrm{~km} / \mathrm{h}$, which is equipped with tread brakes using the repair compound brake block. Moreover, Li et al. [17] 

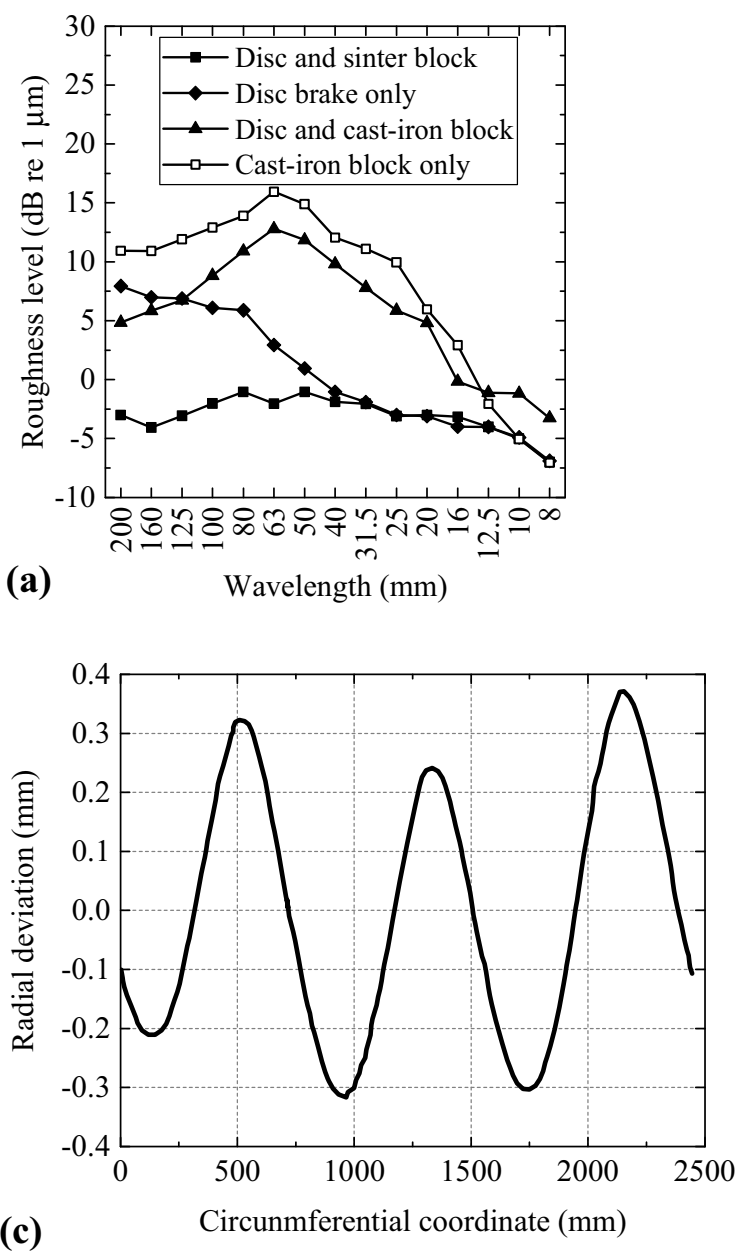
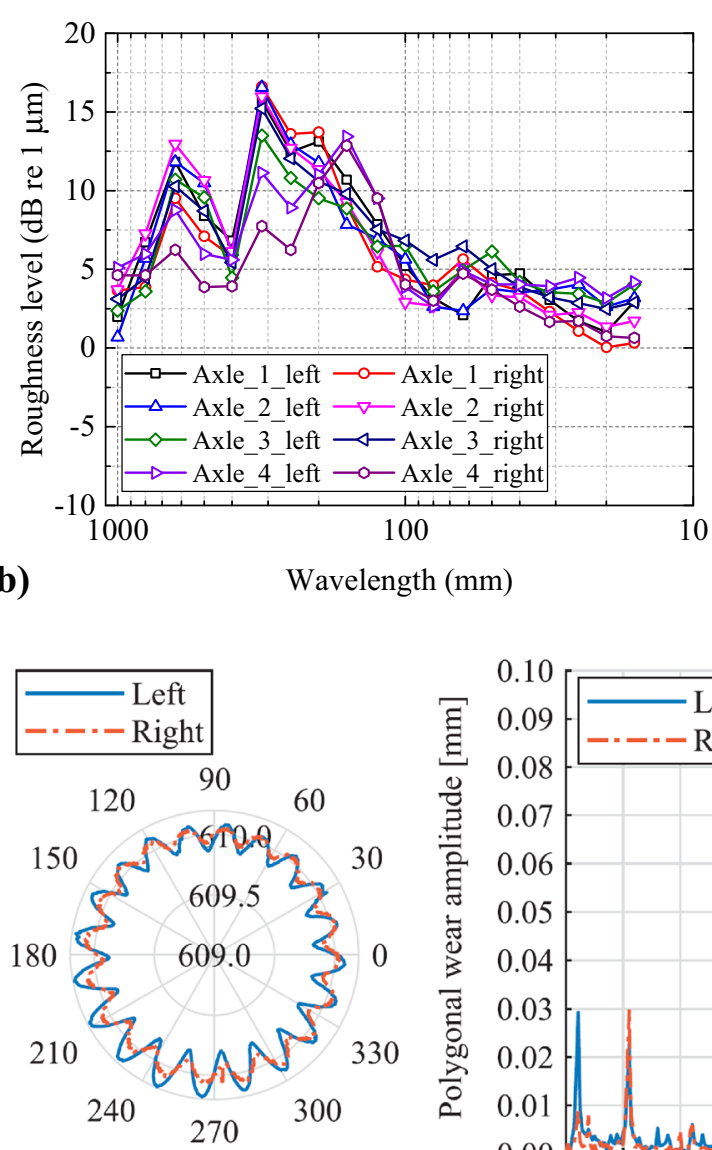

(d)

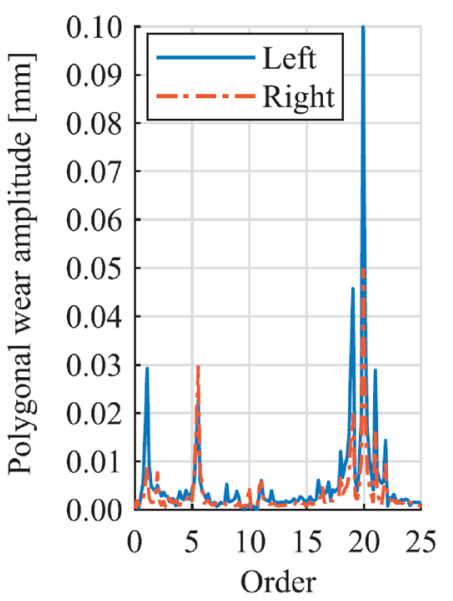

Fig. 1 a Wheel corrugation with wavelengths of $50-70 \mathrm{~mm}$ measured in the Dutch railway [9] described in 1/3-octave bands; b wheel polygonisation with dominant wavelengths of $315 \mathrm{~mm}$ and $630 \mathrm{~mm}$ of TRAXX locomotive wheels measured in Switzerland [11] and described in 1/3-octave bands; $\mathbf{c}$ wheel polygonisation with three harmonics of metro train wheels measured in Sweden [5] and described in the Cartesian coordinate system; and $\mathbf{d}$ wheel polygonisation with 20 harmonics of locomotive wheels measured in South Africa [12] and described in both polar coordinates and special spectrum

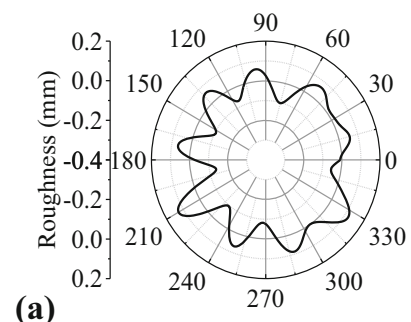

(a)

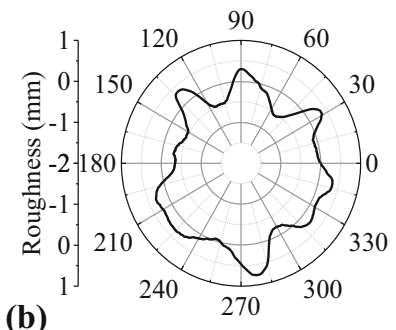

(b)

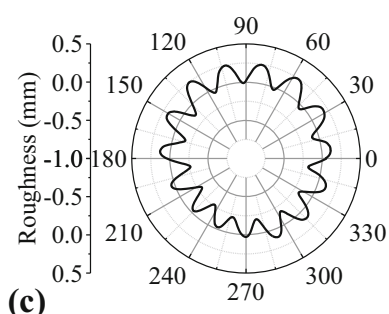

(d)

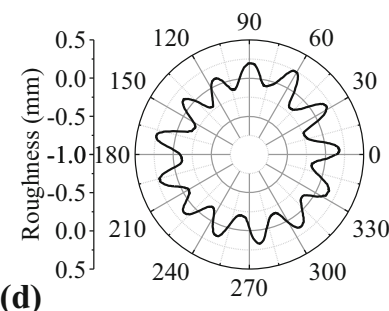

Fig. 2 Typical measurement results of polygonal wear of metro train wheels in China are described in polar coordinates: a LIM metro train with a maximum operating speed of $90 \mathrm{~km} / \mathrm{h} ; \mathbf{b}$ type-B metro train with a maximum operating speed of $80 \mathrm{~km} / \mathrm{h}$; $\mathbf{c}$ type-A metro train with a maximum operating speed of $80 \mathrm{~km} / \mathrm{h}$; and $\mathbf{d}$ type-B metro train with a maximum operating speed of $120 \mathrm{~km} / \mathrm{h}$. The nominal wheel diameters of the LIM metro train and the other three types of metro trains are $730 \mathrm{~mm}$ and $840 \mathrm{~mm}$, respectively

reported that type-B trains in one line of the Nanjing metro also suffered from wheel polygonal wear and the dominant harmonic order was 7. Two types of freight traffic locomotives produced by the same manufacturer suffered from serious polygonal wear problems with centre wavelengths ranging from 160 to $315 \mathrm{~mm}$ in 1/3-octave bands, and the dominant harmonic orders were 18, 19, and 24 [18]. Figure 4 shows typical measurement results. Yang et al. [19] 


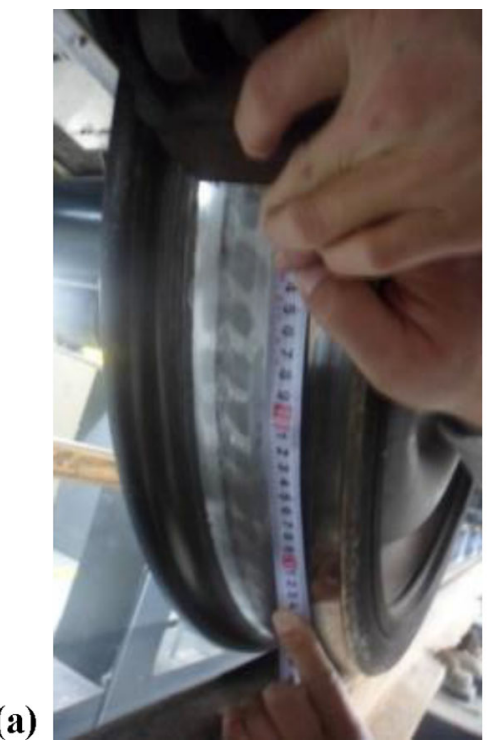

(b)

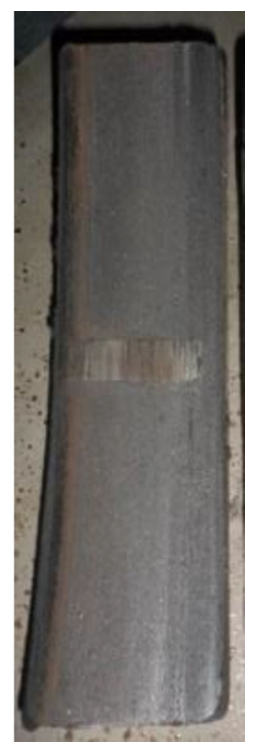

Fig. 3 a Wheel corrugation with a wavelength of approximately $30 \mathrm{~mm}$ on a type-B metro train with a maximum operating speed of $80 \mathrm{~km} / \mathrm{h}$ equipped with tread brakes using the b repair compound brake block

also reported that one type of freight traffic locomotive suffered from serious wheel polygonal wear with dominant harmonic orders of 17-19 and 24. Although the wheel polygonal wear reported in [19] is very similar to that reported by the authors [18], the locomotives are produced by different manufacturers. Some types of high-speed trains in China also exhibited wheel polygonal wear, such as polygonal wear with wavelengths of $100-120 \mathrm{~mm}$ occurring on CRH2 EMU operating in the GuiyangGuangzhou high-speed railway line, with wavelengths of 140-160 mm on CRH3 EMU, and with a wavelength of $100 \mathrm{~mm}$ in 1/3-octave bands on CRH5 EMU operating in Lanzhou-Urumqi high-speed railway line. The typical measurement results of polygonal wear of the high-speed train wheels investigated by the authors' research team are shown in Fig. 5. In summary, periodic wheel defects appear widely in railway field.

\section{Effects of wheel polygonisation}

\subsection{Effects of wheel polygonisation on wheel-rail interaction}

The wheel-rail contact forces fluctuate continuously due to wheel polygonal wear. The frequency is very high, especially for high-speed trains, which can reach approximately $600 \mathrm{~Hz}$. The wheel-rail contact forces are difficult to detect using an instrumented wheelset with a strain gauge, owing to limitations of the current measurement technology. However, the wheel-rail contact forces are very important for analysing the effects of wheel polygonisation. Therefore, simulation is a viable approach for determining the relationship between the wheel-rail contact forces and wheel radius deviation. Moreover, some experimental results were reported using a track-based impact load detection system.

\subsubsection{Simulation}

Morys [20] studied the effects of the low-order OOR (1-5 orders) of high-speed trains on the normal contact force and wheel OOR enlargement. The research results indicated that the stiffness of the substructure significantly influences the normal force variation. The stiffer the substructure, the larger the normal force variation. Moreover, the phase deviation between the normal contact force and wheel OOR is dependent on the excitation frequency of the wheel OOR. Li et al. [21] also found that there is a phase difference between the polygonal wear distribution and the resulting normal contact force. However, the reason for this was not explained. The phase relationship between wheel irregularities and wheel-rail interaction may play a key role in the development of wheel OOR. This gap was filled by Liu and Zhai [22], who found that the wheel-rail contact force is nearly consistent with the derivative of wheel irregularities when the excitation frequency is high (see Fig. 6). This means that the wheel-rail contact force (a)

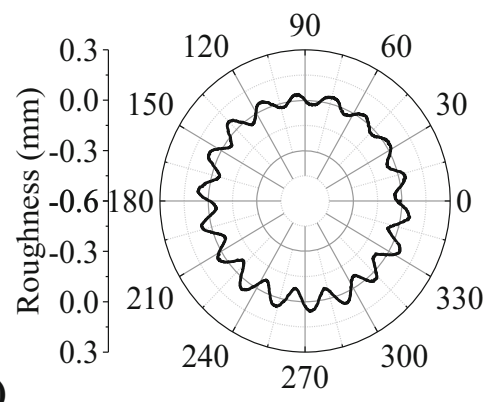

(b)

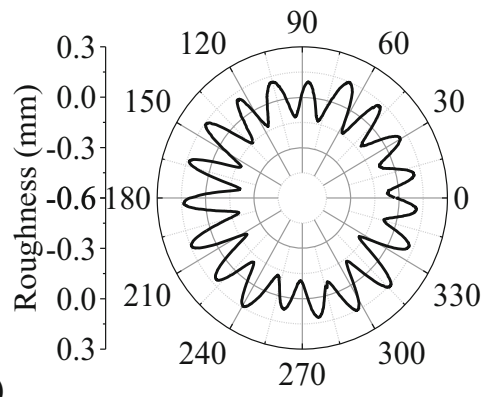

(c)

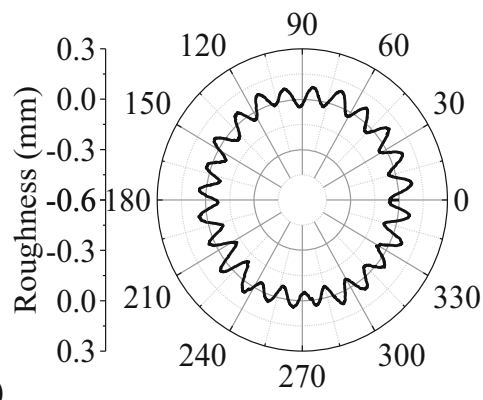

Fig. 4 Typical measurement results of polygonal wear of locomotive wheels with a 18 harmonics, b 19 harmonics, and c 24 harmonics described in polar coordinates [18]. The nominal wheel diameter is $1250 \mathrm{~mm}$ 
(a)

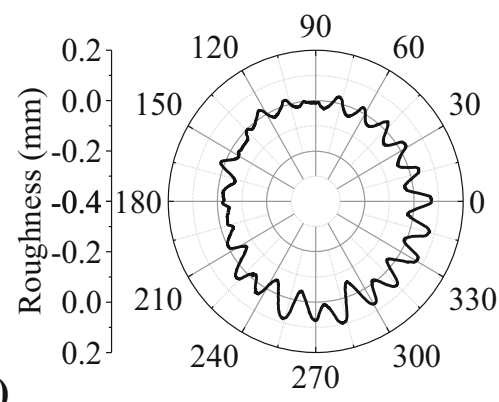

(b)

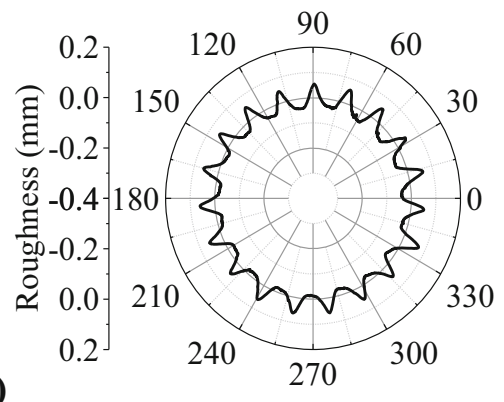

(c)

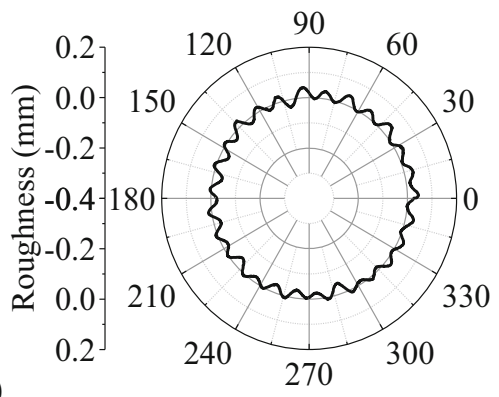

Fig. 5 Typical measurement results of polygonal wear of high-speed train wheels in China described in polar coordinates: a CHR2 EMU, b CRH3 EMU, and c CRH5 EMU with nominal wheel diameters of $860 \mathrm{~mm}, 920 \mathrm{~mm}$, and $890 \mathrm{~mm}$, respectively

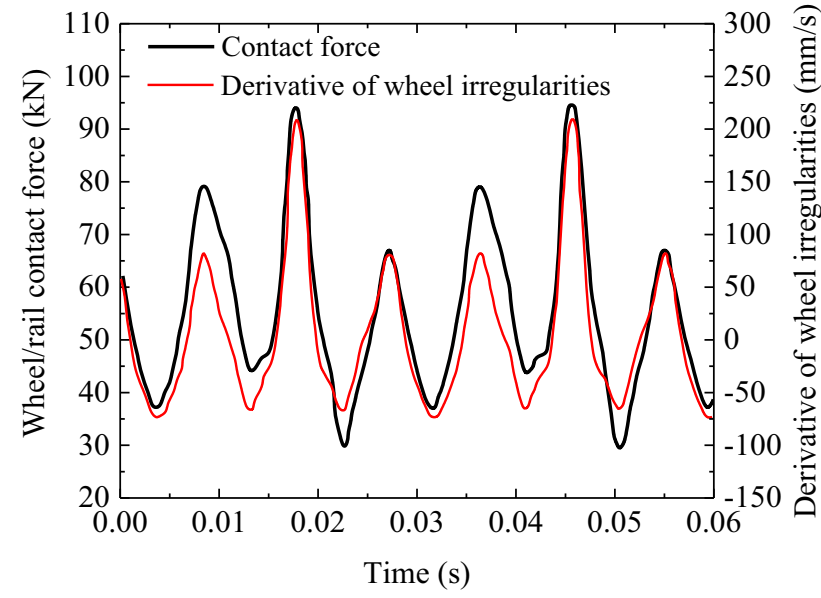

Fig. 6 Time history of wheel-rail contact force and derivative of wheel irregularities at $350 \mathrm{~km} / \mathrm{h}$ [22]

depends on not only the radial run-out of the wheel OOR, but also on the derivative of the wheel irregularities. Therefore, both the radial run-out and derivative of the wheel polygonal wear should be considered in the formulation of wheel re-profiling criteria. That is to say, the wheel radial run-out for the polygonal wheel with shorter wavelength should be controlled more strictly, because the shorter the wavelength, the larger the derivative of the wheel irregularity, which can cause a higher wheel-rail impact force.

An interesting phenomenon of wheel-rail interaction under the excitation of wheel polygonisation was reported by $\mathrm{Wu}$ et al. [23] through a vehicle-track coupled dynamics simulation. If high-order polygonal wear is only set on the front wheelset, the wheel-rail contact forces of the rear wheelset of the same bogie also fluctuate with the same time interval, but the amplitude is much lower. However, if the flexibility of the track is neglected, this phenomenon disappears. That is, a vibration wave induced by high-order wheel polygonal wear can propagate more easily along the flexible track than along the flexible bogie. Furthermore, the wheel-rail interaction is more serious if only one wheel of the bogie exhibits high-order polygonal wear. During an on-track experimental investigation, $\mathrm{Qu}$ et al. [24] found that if one wheelset of a bogie exhibits serious high-order polygonal wear and the other one is reprofiled well, polygonal wear of the re-profiled wheelset develops rapidly. Just after running for $2121 \mathrm{~km}$, the roughness level of the well-re-profiled wheel increased from -15.92 to $10.42 \mathrm{~dB}$ re $1 \mu \mathrm{m}$, and the axle box's vertical acceleration increased from $100 \mathrm{~g}$ to $400 g\left(g=9.81 \mathrm{~m} / \mathrm{s}^{2}\right)$. These conclusions are meaningful for the maintenance of the polygonised wheelset. The two wheelsets of the same bogie should be re-profiled at the same time for polygon-caused re-profiling.

Except for the normal contact, wheel polygonisation also has an obvious influence on the tangential contact. If a natural vibration of the wheelset is excited by wheel polygonal wear, the lateral contact force and lateral velocity of the contact point (or lateral creep) will increase significantly $[25,26]$, which will further promote the development of wheel polygonisation. Lan et al. [27] found that wheel OOR can induce severe fluctuation of the wheel-rail interaction under braking conditions, especially for wheel-rail friction power, which can significantly increase the wear of the wheel and rail.

Most of the simulations of wheel-rail interaction under excitation of wheel polygonisation were performed with a vehicle-track dynamics model, where Hertzian springs were employed to represent the normal contact between the wheel and rail. Generally, wheel polygonal wear, especially high-order polygonal wear, can excite mid-highfrequency vibration of the wheel-rail system. However, the accuracy of the Hertz spring in the mid-high-frequency bands is worth exploring. Zhang et al. [28] investigated the influence of contact modelling on high-frequency wheelrail interaction. Three models, that is, the vehicle dynamic model (rigid multibody dynamic model, ignoring the flexibility of the track and wheelset, named MI), wheelsettrack coupled dynamic model (rigid wheelset, but considering the flexibility of the track, named MII), and 3D 
transient finite element model of the wheel-track rolling contact (MIII) were built. Compared to MIII, MI, and MII overestimated the contact forces, especially for MI, but the phases of the wheel-rail contact forces calculated by the three models were the same. Kou [29] studied the dynamic responses of high-speed wheel polygonisation using a 3D transient finite element model developed by Zhao et al. [30]. The dynamic responses within the contact patch, such as contact pressure, tangential stress, friction power, stickslip distribution, and plastic deformation, were analysed in detail. Typical simulation results are shown in Fig. 7. Moreover, the response behaviour of the wheel material was preliminarily revealed. An elastic-plastic material model measured under different strain rates was employed in the numerical model. Compared with bilinear elasticplastic model, the contact patch is enlarged due to plastic deformation for elastic-plastic model considering strain rates, which results in lower contact stresses and Von Mises equivalent stresses, and residual stresses and strains after rolling. Typical simulation results are presented in Fig. 8. Liu and Jing [31] also studied the high-speed wheel-rail interaction caused by wheel polygonisation using the finite element method.

According to the literature, the flexibilities of the track structure and wheelset should be considered in the study of the wheel-rail interaction under the excitation of wheel polygons. Although much work has been done to investigate the effects of wheel polygonisation on wheel-rail interaction, the sensitivity of wheel-rail contact forces to the characteristics of wheel OOR, such as wavelength, radial run-out, and derivative of wheel irregularities, needs to be further investigated. Meanwhile, the influence of the vehicle velocity, unsprung mass, stiffness, and damping of the rail fastening system should also be considered. The sensitivity analysis results may be helpful for the development of the removal criteria of wheel OOR, which at present is mainly limited by radial run-out.

\subsubsection{Experiment}

Several published papers have reported impact load detection based on strain gauges installed on the rails. Johansson and Nielsen [32] presented wheel-rail contact forces caused by out-of-round wheels through field tests, including wheel flats, long local defect, and periodic OOR (order 4 with an amplitude of $0.5 \mathrm{~mm}$ and order 10 with an amplitude of $0.125 \mathrm{~mm}$ ). Because the wheel-rail contact forces induced by the periodic OOR were much lower than for the other two types of wheel OOR, the periodic OOR attracted little attention at that time. Some researchers have
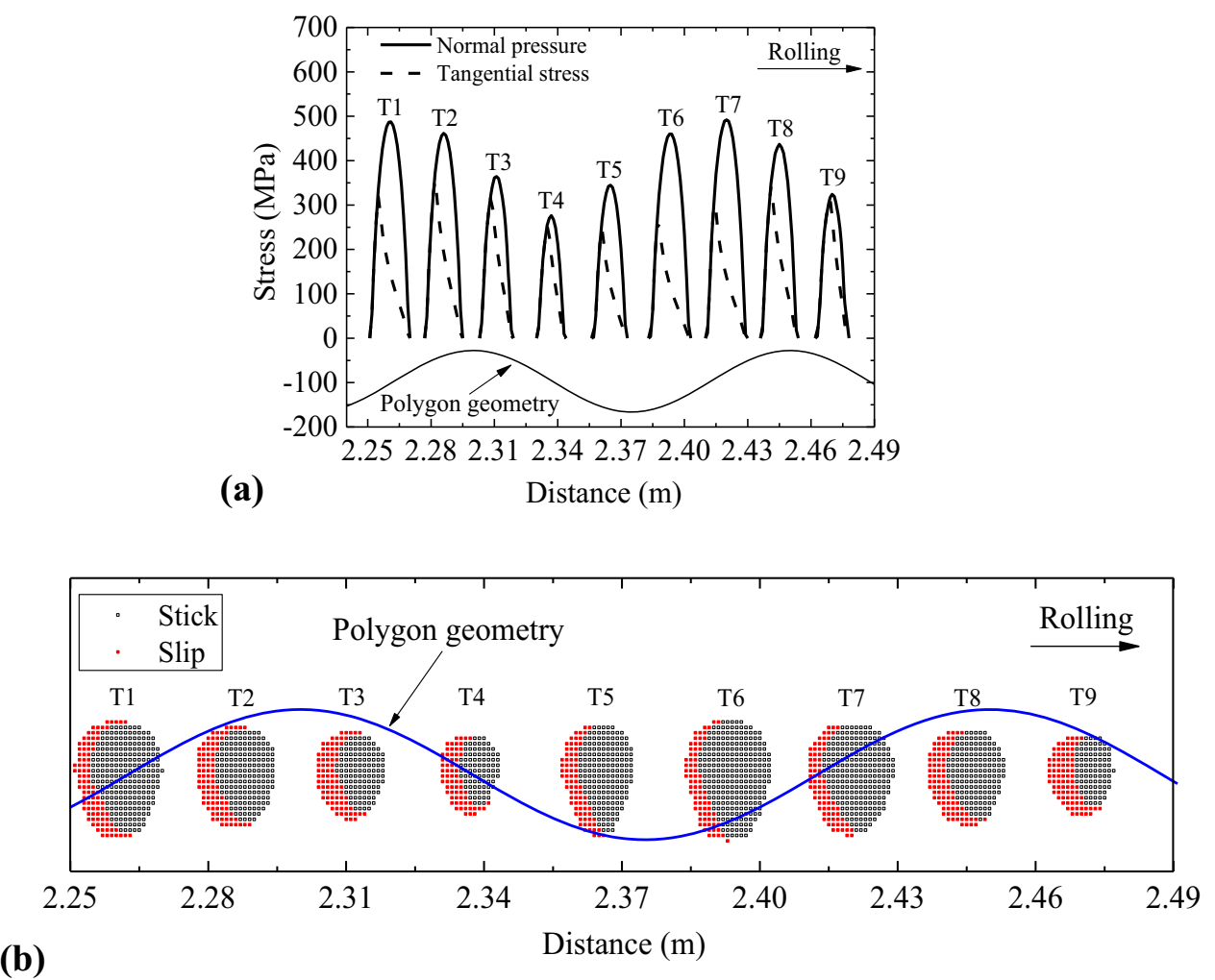

Fig. 7 a Dynamic response of contact stress distribution and b stick-slip distribution within contact patch [29]. The running speed is $300 \mathrm{~km} / \mathrm{h}$, and the wavelength of wheel polygonal wear is approximately $150 \mathrm{~mm}$ 


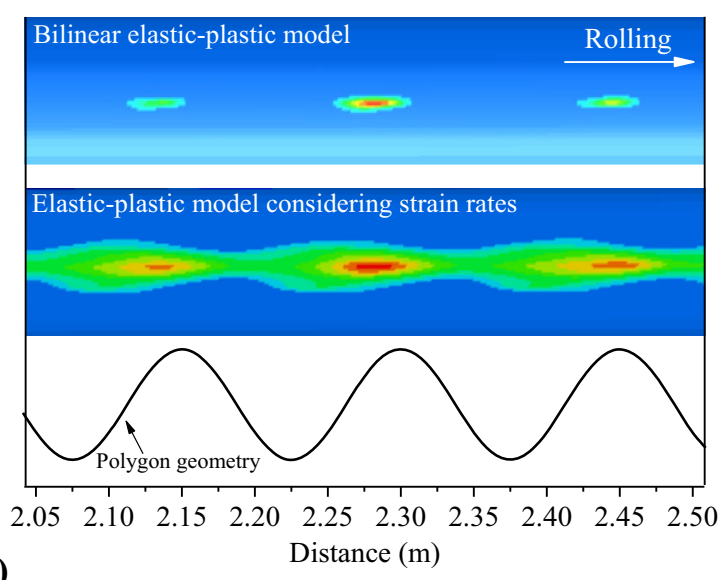

(a)
Distance (m)

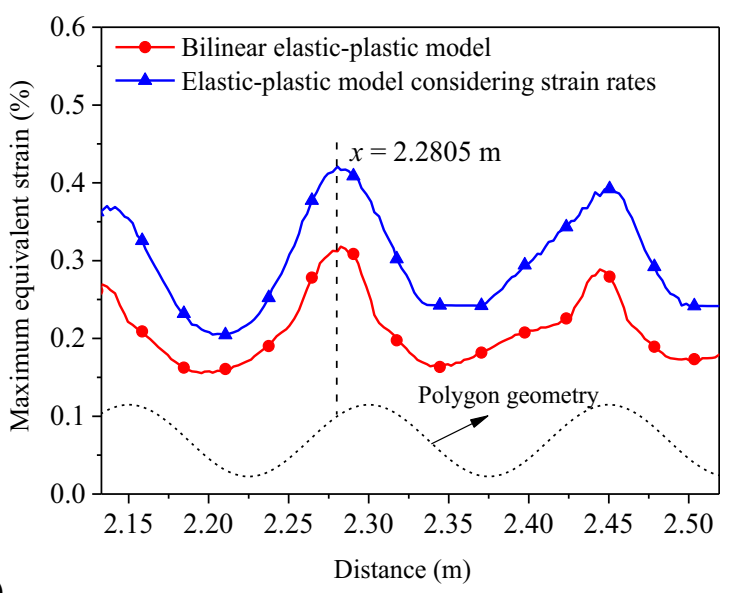

(b)

Fig. 8 a Equivalent plastic deformation and $\mathbf{b}$ equivalent strain calculated by different material models [29]

adopted a wheel impact load detection system based on a rail-mounted strain gauge to identify and monitor wheel defects. Special efforts were made to improve the original detection system to help the system acquire the ability to detect periodic OOR wheels, for example, Reitmann et al. [12] and Li et al. [33].

However, some shortcomings of the detection of wheelrail forces caused by wheel polygonisation through a rail strain gauge should be overcome. Because the installation position of the system is fixed and the strain gauges are generally installed on the rail between two sleepers, it is very difficult to ensure that the wheels contact the rail at the most serious position of the wheel OOR, especially for discrete wheel defects. Moreover, the accuracy of the system depends on the wheel diameter, sleeper distance, and number of instrumented sleeper bays. Therefore, it is necessary to design an indirect measurement system installed on the vehicle to detect the wheel-rail contact forces induced by wheel polygonisation, which is very helpful for understanding the formation mechanism and the effects of wheel polygonisation.

\subsection{Effects of wheel polygonisation on vibration and noise}

Wheel polygonisation can cause severe fluctuations in the wheel-rail contact forces, which produce vibrations on the wheelsets and rails. Subsequently, the vibration can transmit upward to all parts of the vehicle and downward to the components of the track. Moreover, the fluctuation of wheel-rail contact forces can lead to considerable noise emission from the wheel-rail system, which can increase the interior and exterior noise of the train.

\subsubsection{Effects of wheel polygonisation on vibration}

According to the traditional design theory of railway vehicles, the suspension system can effectively isolate the mid-high-frequency vibration from wheel-rail excitation. However, field test results indicate that this is not always true. Wheel polygonisation-induced vibration sometimes can be transmitted to the car body and thus lead to its abnormal vibration [34]. The test results presented by the authors in Ref. [34] showed that the vibrations in the range of $60-100 \mathrm{~Hz}$ had the highest contribution to the car body, as shown in Fig. 9, which was caused by wheel polygonal wear. Nevertheless, the vibration transmission path is not very clear. To the best of the authors' knowledge, the suspended rod of the gear box and the vertical damper of the primary suspension may play a key role in transmitting the vibration from the wheelset to the bogie frame, and the vertical damper of the secondary suspension may be responsible for transmitting the vibration from the bogie frame to the car body.

Because some types of high-speed trains suffered from serious high-order polygonal wear in China, extensive tests and simulations were carried out to investigate the effects of wheel polygonisation on the vehicle and track vibration. $\mathrm{Qu}$ et al. [24] presented some interesting test results. In their test scheme, three wheelsets of a vehicle were reprofiled (wheelsets No. 1, 2, and 4); however, the remaining wheelset (wheelset No. 3) suffered from serious high-order polygonal wear with 18 harmonics. Wheelsets 1 and 2 were on a bogie, while wheelsets 3 and 4 were on another bogie. The axle box vertical acceleration of wheelset 4 increased from $100 \mathrm{~g}$ to $400 \mathrm{~g}$ after a running distance of $2121 \mathrm{~km}$. Moreover, the polygonal wear of wheelset 4 also developed rapidly. They deduced that the vibration induced by high-order polygonal wear was transmitted through the rail. Meanwhile, the rail natural 


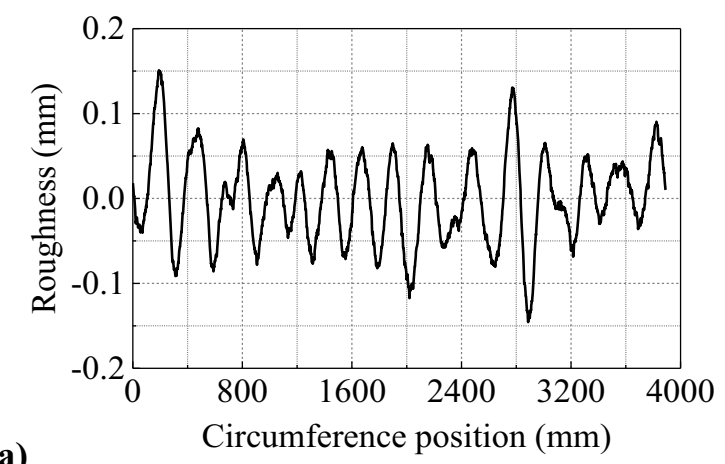

(a)

(b)

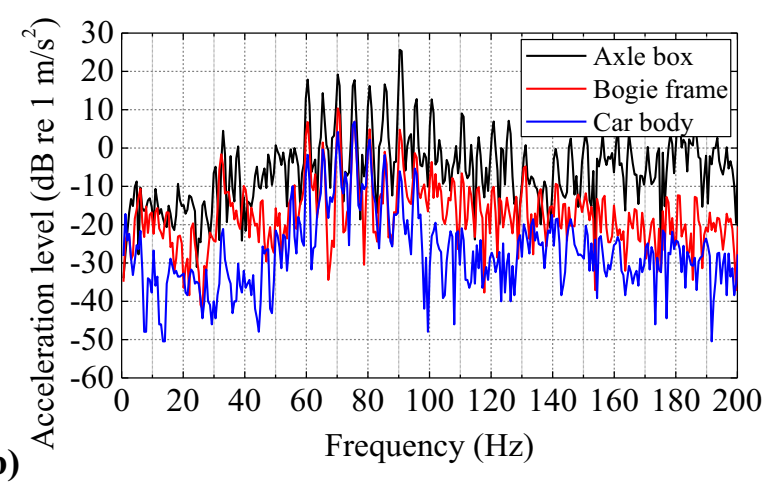

Fig. 9 Polygonisation-induced vibration of locomotive [34]: a wheel polygonal wear measurement results and $\mathbf{b}$ vertical acceleration spectra of the axle box, bogie frame, and car body of the locomotive

vibration between the two wheelsets of the same bogie was excited by wheel polygonal wear, which caused a considerable increase in the vertical acceleration and rapid development of polygonal wear of wheelset 4 . Wu et al. [35] investigated the cause of the axle box bolt of a highspeed train self-loosening and found that the high-order wheel polygonisation excited some eigenfrequencies of the axle box and axle box end cover. The acceleration of the axle box end cover was amplified compared to the axle box. Under the severe oscillation condition, the bolts of the axle box end cover came loose. Wu et al. [36] revealed the correlation of axle box vertical acceleration and wheel roughness magnitude by summarizing the results of a sixmonth long field measurement campaign in China, which suggested that the axle box acceleration can serve as a good measure for detecting wheel polygonisation and thereby determines the wheel-removal criterion. A long-term tracking test of wheel polygonal wear and vibration was performed on a newly designed high-speed train with the nominal speed of $250 \mathrm{~km} / \mathrm{h}$ by the authors' research team [37]. The feature and evolution law of wheel polygonisation and axle box acceleration were achieved, which is very helpful for the operation and wheelset maintenance of high-speed trains.

Accelerometers were installed on the axle box in most tests to investigate the mechanism or the effects of wheel polygonisation. Because the wheelset is a rotating component, its vibration feature may differ from that of the axle box, especially under high-speed conditions. Owing to gyroscopic effects, each peak in the frequency-response function associated with a mode with multiplicity 2 yields two resonances [38-41]. However, if the accelerometer is installed on the axle box, the frequency bifurcation phenomenon cannot be captured. Thus, it is necessary to test the vibration of the wheel. Wang et al. [42] studied the vibration transmission of a high-speed train with polygonised wheels through a field test. The KMT telemetry device was used to measure the acceleration of the wheel web and wheelset axle. The acceleration of the axle box was measured by ordinary way. The time-frequency spectrum of the wheel and axle box is shown in Fig. 10. An interesting phenomenon was observed that the dominant frequency of the axle box acceleration was equal to the passing frequency of the wheel polygon. However, the acceleration on the wheel showed significant side frequencies, which means that there were two dominant frequencies on the wheel acceleration: one at the lower frequency and the other at the higher frequency. That is, the vibration induced by wheel polygonisation exhibited a frequency bifurcation phenomenon under high-speed conditions. A beat vibration phenomenon was also observed, which considerably increased the overall vibration.

Although high-order wheel OOR attracts more attention, the influence of the low-order wheel OOR cannot be ignored. The excitation frequency of the wheel eccentricity is generally less than $10 \mathrm{~Hz}$ for an ordinary-speed vehicle, which can easily transmit to the car body and lead to a decrease in ride comfort. Lv et al. [43] and Jiang et al. [44] reported the influence of wheel eccentricity on the vertical vibration of suspended monorail vehicles and straddle monorail vehicles, respectively. The abnormal vibration of the two types of monorail vehicle was mainly caused by wheel eccentricity, although they were equipped with a solid tire rather than a steel wheel.

Compared to those on the vehicle, the effects of wheel polygonisation on the track are much smaller, although wheel polygonisation can cause severe vibration of the rails and fastening clips. The influence of wheel polygonal wear on high-speed railway bridges and subgrades was investigated numerically by Han et al. [45] and Chen et al. [46]. It was found that the wheel polygon wear had a non-negligible effect on the bridge [45] and subgrade [46]. Meanwhile, wheel OOR is one of the two main vehicle parameters that affect ground vibration [47, 48]. 

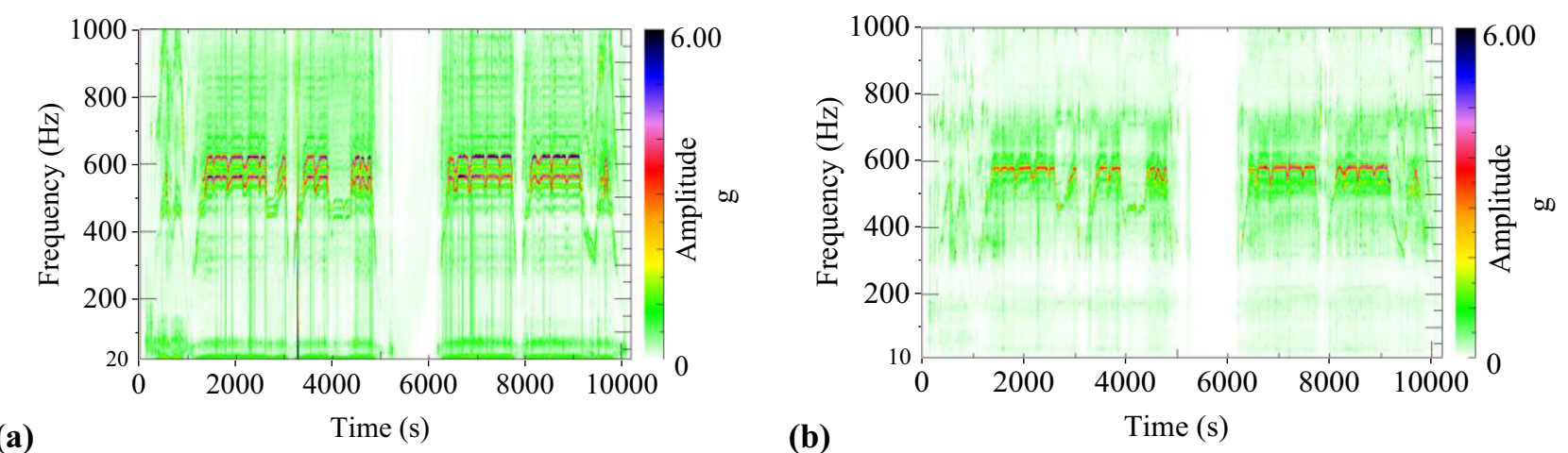

Fig. 10 Time-frequency spectrum of $\mathbf{a}$ wheel and $\mathbf{b}$ axle box accelerations of high-speed train excited by high-order wheel polygonal wear [42]

\subsubsection{Effects of wheel polygonisation on noise}

Wheel roughness is an important factor influencing wheelrail rolling noise. Dings and Dittrich [9] investigated the effect of the wheel roughness level on the pass-by noise. The roughness and pass-by noise of different train types with their respective brake types were measured, such as (1) disc + cast-iron block, (2) disc + sinter block, (3) disc only, and (4) cast-iron block only. The relationship between noise and roughness was almost linear except for the sinter block brakes, as shown in Fig. 11. Because the wheels with cast-iron block suffered from serious corrugation with wavelengths of $50-80 \mathrm{~mm}$ (see Fig. 1a), the pass-by noise of the train equipped with cast-iron block was much higher than that of the train equipped with disc brake only.

Wheel polygonisation can induce severe vibration of the wheel-rail system and lead to considerable noise emission from the wheel-rail interface. As mentioned in Sect. 2, LIM metro train wheels suffered from polygonal wear with nine harmonics. Fang et al. [49] used a combined FEMBEM acoustic model to determine the effect of the

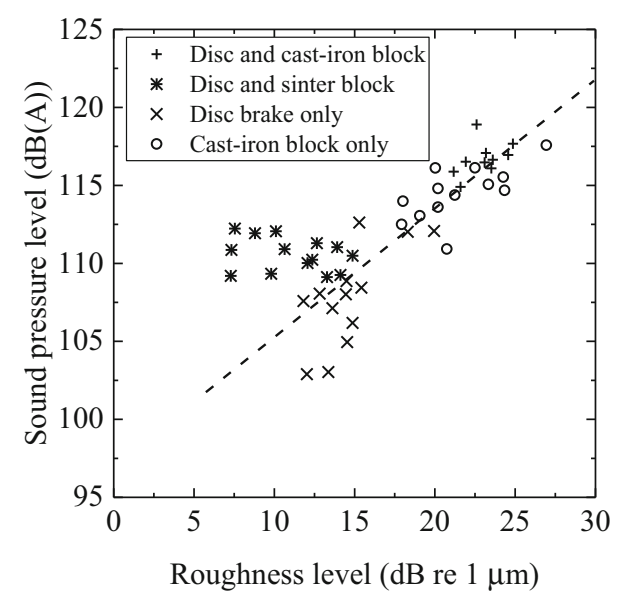

Fig. 11 Sound pressure pass-by level versus wheel roughness [9] polygonal wear evolution of LIM metro train wheels on the vibration and sound radiation of the wheel and found that the wheel noise radiation decreased by $6 \mathrm{~dB}(\mathrm{~A})$ after reprofiling. The authors' research team reported an abnormal interior noise phenomenon in a high-speed dining coach [50-52]. Through theoretical analysis and field experiments, it was found that the special interior structure that changes the interior diffuse sound field was the root cause of this abnormal interior noise, and high wheel roughness had a significant contribution to the interior noise. Typical measurement results are shown in Fig. 12. One wheel of the dining coach before re-profiling exhibited polygonal wear with 19th harmonic order, corresponding to a wavelength of approximately $150 \mathrm{~mm}$. Furthermore, a long local defect occurred on the wheel, the length and depth of which were $310 \mathrm{~mm}$ and $0.794 \mathrm{~mm}$, respectively. Wheel polygonisation of the dining coach caused severe vibration and noise. After re-profiling, the noises in the bogie region and coach interior decreased by 9 and $11 \mathrm{~dB}(\mathrm{~A})$, respectively. The effects of wheel polygonal wear on wheel-rail noise and interior noise of high-speed trains were further investigated using the track-wheel interaction noise software (HWTNS) and the vibroacoustic analysis software VA One 2012, respectively. The effects of polygonal wear orders, roughness levels, and phases on noise were analysed in detail.

Wheel polygonisation cannot only cause wheel-rail noise, but can also induce vehicle structure vibration, which may lead to considerable noise emission. The noise caused by the wheel polygonisation should be taken into account when developing the re-profiling criterion for the polygonised wheel.

\subsection{Effects of wheel polygonisation on fatigue reliability of vehicle and track components}

Wheel polygonisation can cause fluctuations in the wheelrail forces and oscillations of vehicle and track 


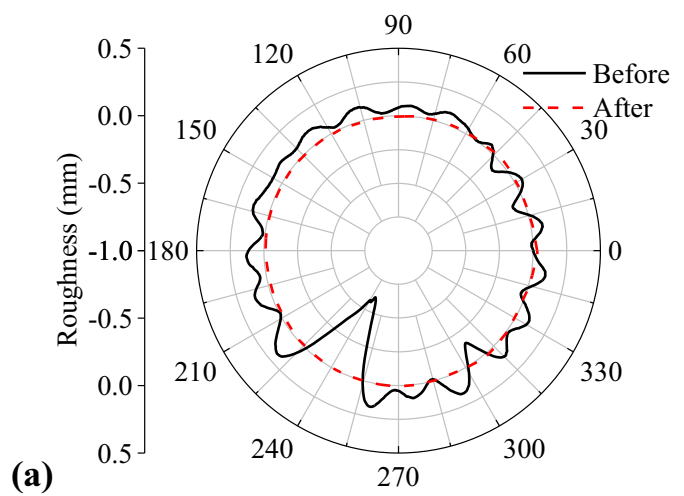

(b)
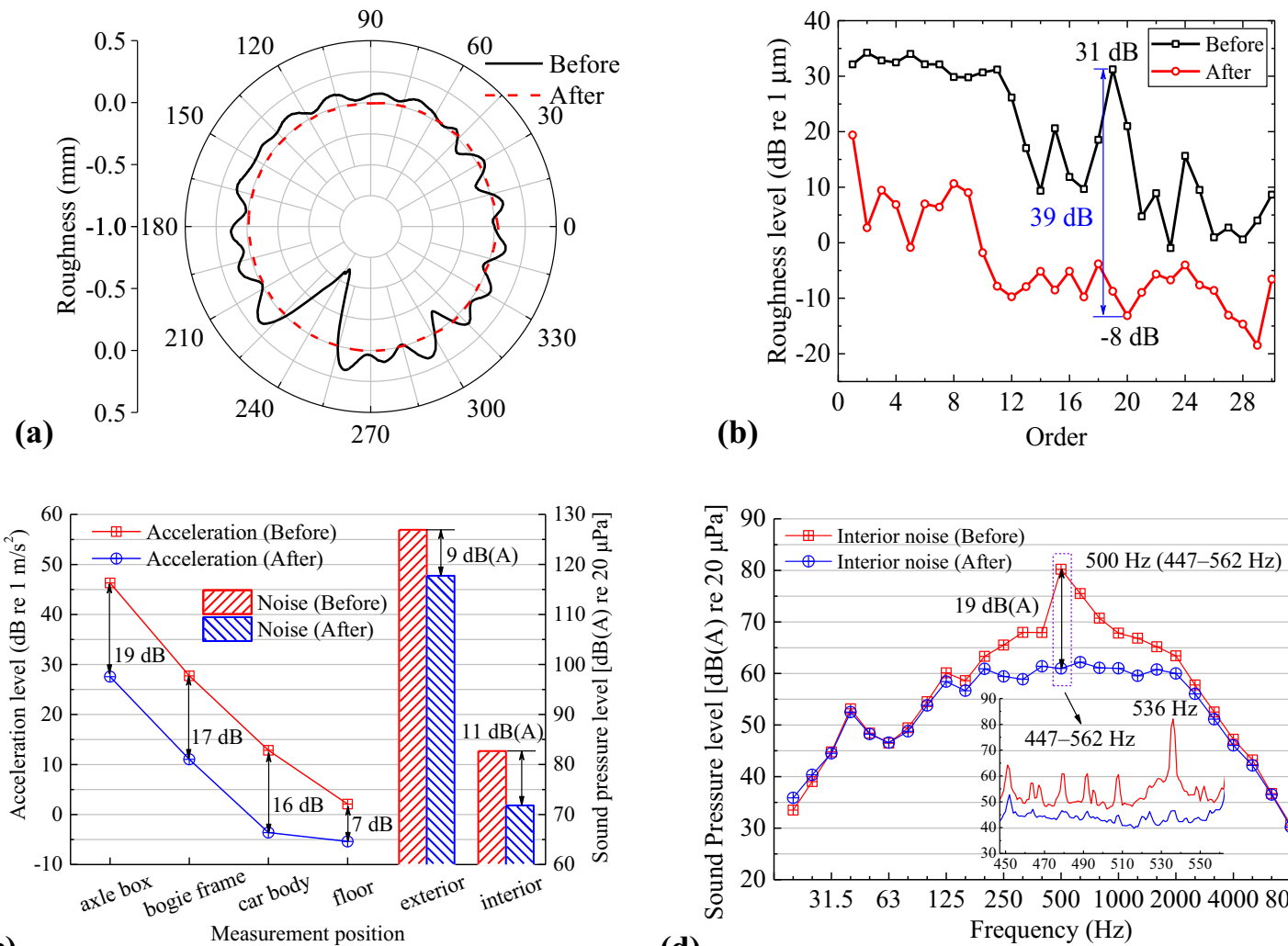

(c)

(d)

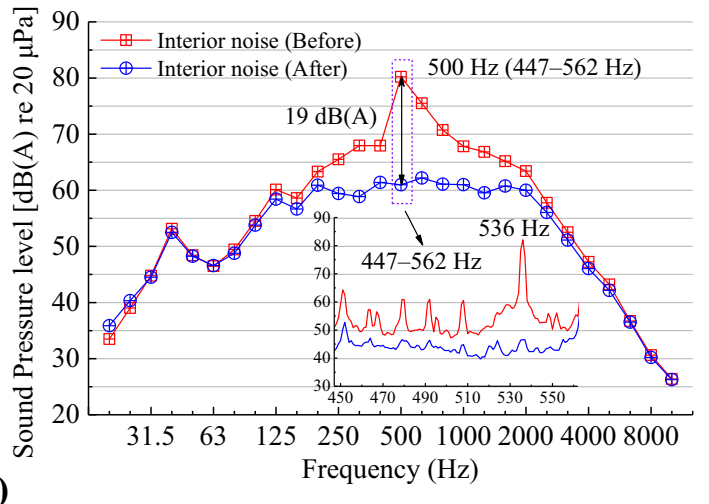

Fig. 12 Noise and vibration of high-speed train caused by wheel polygonisation [51]. Wheel roughness is described in a polar coordinates and b harmonic orders. Noise and vibration before and after wheel re-profiling: c overall levels and $\mathbf{d}$ 1/3-octave band and narrowband spectrum

components. Under the condition of cyclic alternating load, the fatigue cumulative damage of the structure will be affected. Unfortunately, if a natural mode frequency of the structure is close to the excitation frequency of the wheel polygonisation, the fatigue life may significantly decrease.

Wu et al. [23, 53, 54] investigated the effect of highorder polygonal wear of high-speed train wheels on the wheelset axle stress and damage tolerance through numerical simulation. A vehicle-track rigid-flexible coupled dynamics model was employed to estimate the dynamic response of the vehicle-track system under the excitation of the wheel polygonisation. The modal stress recovery method was used to calculate the dynamic stress of the wheelset axle. The elastic structure vibration of the wheelset axle was excited by wheel polygonisation. The dynamic stress of the wheelset axle increased sharply in the resonance region of the wheelset, and the residual lifetime of the wheelset axle decreases considerably. It was pointed out that it is necessary to consider the effect of wheel polygonisation on dynamic stress to determine the wheel re-profiling interval.

The gearbox housing is a critical component of powered vehicles in railway trains. Its service environment is very complicated. The gearbox housing suffers from not only the internal excitation generated by gear meshing, but also external excitation, including the drive torque from the motor and dynamic load from the wheel-rail impact. The first fatigue failure case on a high-speed EMU gearbox housing in China was reported in June 2012, and since then to early 2016, more than a hundred gearbox housings were cracked [55]. Much research has been done to investigate the cause and influence factors of gearbox fatigue failure. Initially, a large number of field measurement results indicated that the dominant frequency of acceleration and dynamic stress of the gearbox was approximately $580 \mathrm{~Hz}$ when the train speed reached its commercial operating speed of $300 \mathrm{~km} / \mathrm{h}$. A numerical modal analysis of the gearbox housing showed that there is a natural vibration mode near $580 \mathrm{~Hz}$ (see Fig. 13). The excitation from the wheel-rail system could excite the resonance of the gearbox housing, which caused fatigue failure of the gearbox housing [56]. Hu et al. [57] also investigated the formation of fatigue cracks in gearbox housings of high-speed trains through field experiments and numerical modal analysis. The external excitation from the wheel-rail system excited the first two modes of the gearbox housing, which significantly increased the dynamic stress in the stress concentration region of the gearbox and accelerates its fatigue 


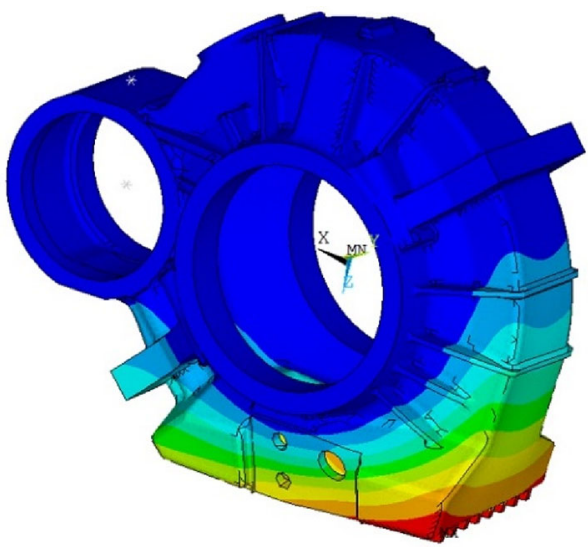

Fig. 13 The first vibration mode of the gearbox housing $(580 \mathrm{~Hz})$ [60]

failure. Moreover, the fluctuation of the dynamic stress of the gearbox housing resulted in a beat phenomenon, which further increased the amplitude of the dynamic stress. Except for the external excitation and natural vibration of the gearbox, casting defects also play a critical role in the fatigue failure of the gearbox, which seriously reduces the fatigue strength of the gearbox. However, the excitation source was not determined by Zhang et al. [56] and $\mathrm{Hu}$ et al. [57]. Yuan et at. [58] deduced that wheel polygonisation was the main excitation source causing resonance of the high-speed EMU gearbox housing. The fatigue failure of high-speed EMU gearbox housings in China has also attracted large amounts of researchers to study this problem through numerical simulation. Wu et al. [59] studied the fatigue damage of the gearbox housing of a high-speed train under wheel polygonisation through numerical simulation. However, they neglected the influence of the gear transmission system. Wang et al. [60-62] performed numerous simulations to investigate the effects of wheel defects, such as polygonisation and flat, on the dynamic performance and fatigue reliability of the gearbox housing. They developed a powerful numerical model that included the vehicle-track coupled dynamics, flexibility of the wheelset and gearbox, and gear transmission system.

Besides the gearbox, the fatigue reliability of other components of vehicles and tracks influenced by wheel polygonisation has also been reported, such as the primary steel coil spring of metro trains [16], primary vertical block of high-speed EMU [63], welded bogie frame of metro trains [64], and clips of the fastening system of high-speed railways [65]. Figure 14 shows some photographs of vehicle and track components that failed due to the excitation of wheel polygonisation in China.

Generally, the excitation frequency induced by wheel polygonisation depends on the train speed. If a natural mode frequency of the vehicle and track components is close to the passing frequency of wheel polygonisation at a normal train speed, a structure resonance could be excited, which has a remarkable influence on the fatigue life of the components.

\subsection{Discussion of the maintenance criteria for wheel polygonisation}

From the literature review presented above, it can be seen that wheel polygonal wear, especially high-order polygonal wear, has a great influence on the wheel-rail interaction, vibration and noise of vehicles, the component reliability of the vehicle-track system, and the economy of operation. This is an important factor restricting the sustainable development of railways. Generally, the maintenance criteria for wheel polygonisation are based on radial run-out. (a)

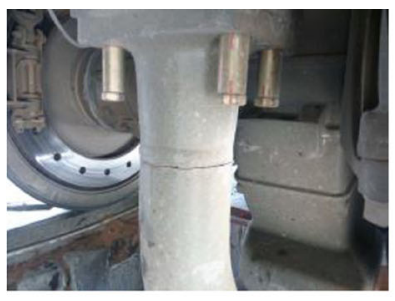

(b)
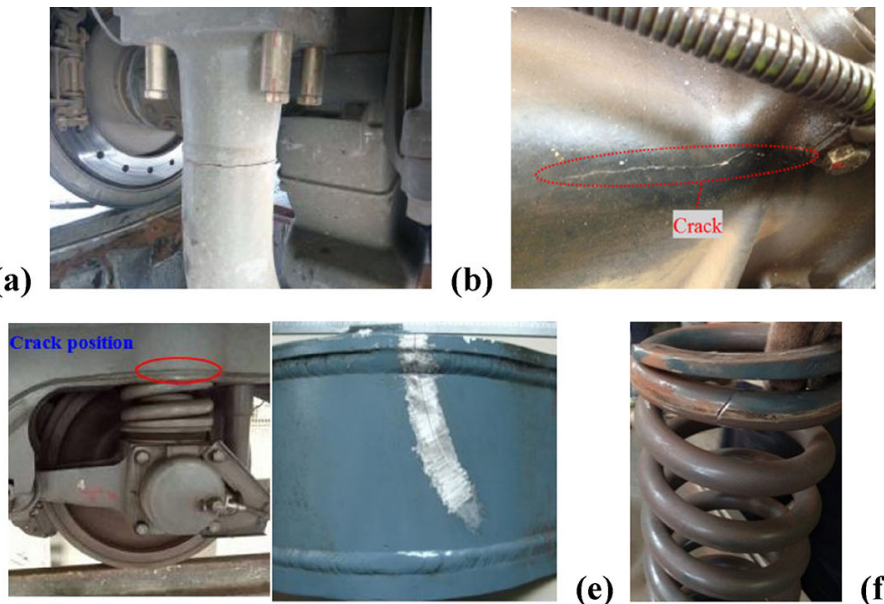

(e)

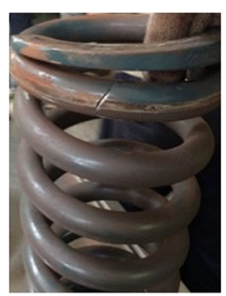

(c)
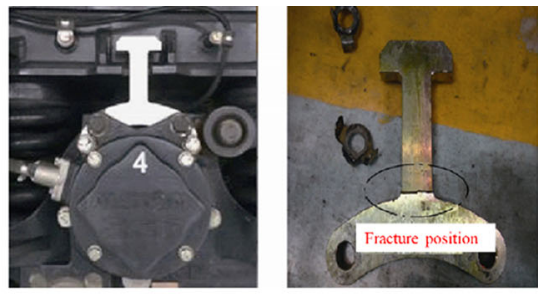

(f)

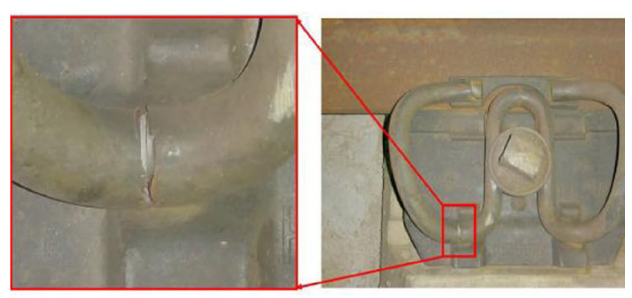

Fig. 14 Failure of vehicle and track components due to the excitation of wheel polygonisation in China: a supporting tube of the sanding device of locomotive [35]; b gearbox housing of high-speed EMU [57]; c vertical block of axle box of high-speed EMU [63]; d welded bogie frame of metro vehicle [64]; e steel coil spring of metro vehicle [16]; and f clip of rail fastener [65] 
According to EN 15313:2016 [66], for a vehicle with a maximum authorized speed less than or equal to $120 \mathrm{~km} / \mathrm{h}$ or exceeding $120 \mathrm{~km} / \mathrm{h}$, the maximum allowable values of the radial run-out are required to be below $0.5 \mathrm{~mm}$ and $0.3 \mathrm{~mm}$, respectively. However, using the radial run-out value to limit the polygonised wheel may not be reasonable. The wavelength and waveform of the wheel polygonisation should be considered. Moreover, it is necessary to consider the effects of wheel polygonisation on wheelrail interaction, noise and vibration, and fatigue reliability of vehicle and track components when proposing wheelmaintenance criteria for the polygonised wheel. Multidisciplinary joint research is required to determine a scientific and reasonable maintenance criterion for a polygonised wheel.

\section{Formation mechanism of wheel polygonisation}

In recent decades, wheel polygonisation has received more attention because it has become a very common problem, especially in China. There are many scientific papers reporting the investigation results of wheel polygonisation or wheel corrugation mechanisms. According to the published papers, the formation mechanism of wheel polygonisation or wheel corrugation can be roughly classified into three categories, namely, (1) initial wheel defects, (2) a natural vibration of the vehicle-track system, and (3) thermoelastic instability. Table 1 summarizes the mechanisms of wheel polygonisation and wheel corrugation.

There are little reports of other damage mechanisms that can lead to wheel polygonisation except for wear damage in published papers. Wheel polygonisation of locomotives, high- and ordinary-speed trains, and metro trains has been investigated by the authors' research team. We had not found wheel polygonisation caused by other damage except wear damage. It is different from rail corrugation. Some corrugation on heavy-haul railway line is caused by plastic deformation. Because the re-profiling interval is generally less than $200,000 \mathrm{~km}$ for the polygonised wheels in China, plastic deformation is not dominant. However, we do not know if there are polygons on the wheels of heavy-haul wagon, especially for the wagon with axle load large than $30 \mathrm{t}$. In the case of high axle load, wheel polygons caused by plastic deformation may appear.

\subsection{Induced by initial wheel defects}

At the end of the twentieth century in Europe, some new wheels and worn ones of high-speed train and metro train suffered from OOR with third harmonic order. Rode et al. [67] indicated that claw clamping in a three-jaw chuck of the wheel during re-profiling may cause an initial polygon 
with three harmonics. Three equidistant points inside the wheel flange are selected for fixing. An elastic deformation of the wheel rim is generated along the radial direction at the fixing point of the clamp. After unloading, the deformation is restored. A small initial irregularity is formed at the three fixed points of the wheel, and it develops continuously in the subsequent operation process, forming significant polygonal wear with three harmonics. If the excitation frequency of the initial third-order irregularity is consistent with a natural frequency of the wheelset, it will develop rapidly [20]. Meinke and Meinke [68] modified Morys' model [20] and took the wheelset rotation and flexibility into account in the simulation model. The formation and evolution of wheel polygonisation caused by static and dynamic imbalances were analysed. They indicated that static and dynamic imbalances can cause wheel polygonisation. Nielsen and Johansson [4] suggested that inhomogeneous material properties of the wheel have a significant influence on two types of wheel OOR, that is, discrete defect and non-periodic OOR. The authors' research team through field investigation and wheel reprofiling process simulation indicated that it is easy to cause serious polygonal wear after wheel re-profiling by using an unreasonable turning process and the spacing of the two driving wheels of the underfloor wheel lathe [69]. Cui et al. [70] and Su et al. [71] found that the eccentricity of the driving wheel of an underfloor wheel lathe can easily lead to the formation of a low-order polygon after wheel reprofiling.

In short, initial wheel defects, such as wheel re-profiling, static and dynamic imbalances, and inhomogeneous material properties of the wheel, are important factors influencing the formation and development of wheel OOR.

\subsection{Induced by natural vibration of the vehicle- track system}

The vast majority of scientific papers use the viewpoint of natural vibration of the vehicle-track system to explain the formation mechanism of wheel polygonisation, including the (1) stick-slip oscillation of the wheel-rail system, (2) P2 resonance, (3) frictional self-excited vibration of the wheelset-track system, (4) lower bending or torsional modes of the wheelset, (5) bending vibration modes of the rail or track, (6) excited resonance of the bogie, and (7) vibration of other components of the bogie.

The periodic wear on wheel-rail surfaces has been widely accepted as a consequence of a combination of a wavelength-fixing mechanism and a damage mechanism. Common wavelength-fixing mechanisms are resonances of the coupled vehicle-track system. That is, the wavelengthfixing is often a resonance frequency of the vehicle-track system and this resonance frequency is fixed. Based on our research results of rail corrugation and wheel polygonisation in China, the mechanism of them is actually attributed to a resonance frequency of the vehicle-track system. Therefore, the authors prefer to use the wording 'frequency-fixing' in this paper. However, in order to express the original meaning of the text of the cited references, when the research results of the cited references are presented in this paper, whether 'wavelength-fixing' or 'frequency-fixing' is used depends on original references.

\subsubsection{Stick-slip oscillation of wheel-rail system}

Kalousek and Johnson [8] presented a detailed investigation process of short pitch wheel and rail corrugations on the Vancouver mass-transit system. Their investigation results showed some slip marks on the wheel and rail surface, which indicated that the wheel-rail system experienced stick-slip oscillation. The cause of the wheel corrugation was the stick-slip oscillation of the wheel-rail system. Moreover, the installation error of the wheelsets had a significant influence on the wheel corrugation. A large installation error of the wheelset can lead to a large yaw angle of the wheelset when the vehicle is running in a straight line, increasing the lateral creepage and the lateral creep force between the wheel and rail, and intensifying the wheel-rail wear.

\subsubsection{P2 resonance}

The P2 force was first reported by Jenkins et al. [72], where the wheelset, rail, sleepers, and/or slab vibrate in phase with the ground stiffness. The P2 resonance is mainly influenced by the track stiffness and unsprung mass. Grassie [73] classified rail corrugation into six categories, three of which are related to P2 resonance. Some papers reported that the $\mathrm{P} 2$ resonance is also an important factor that causes wheel OOR. Generally, the P2 resonance can cause a low-order OOR. Johansson and Andersson [74] simulated the wear evolution of wheel polygonisation, which indicated that the P2 resonance and the sleeperpassing frequency were the wavelength-fixing mechanisms of fifth-seventh-orders OOR. The authors' research team investigated the formation reason of wheel OOR with 5-8 harmonics of metro train wheels [14] and concluded that the P2 resonance was the wavelength-fixing mechanism of wheel OOR with 5-8 harmonics. The rail surfaces of this metro line were fairly smooth, and there was little rail corrugation; however, the wheels suffered from serious OOR with 5-8 harmonics. The dominant frequencies of the axle box vertical acceleration range from 50 to $80 \mathrm{~Hz}$, as shown in Fig. 15, which is caused by the $\mathrm{P} 2$ resonance. The formation mechanism of the wheel OOR reported in [14] was further verified by numerical simulation performed by 

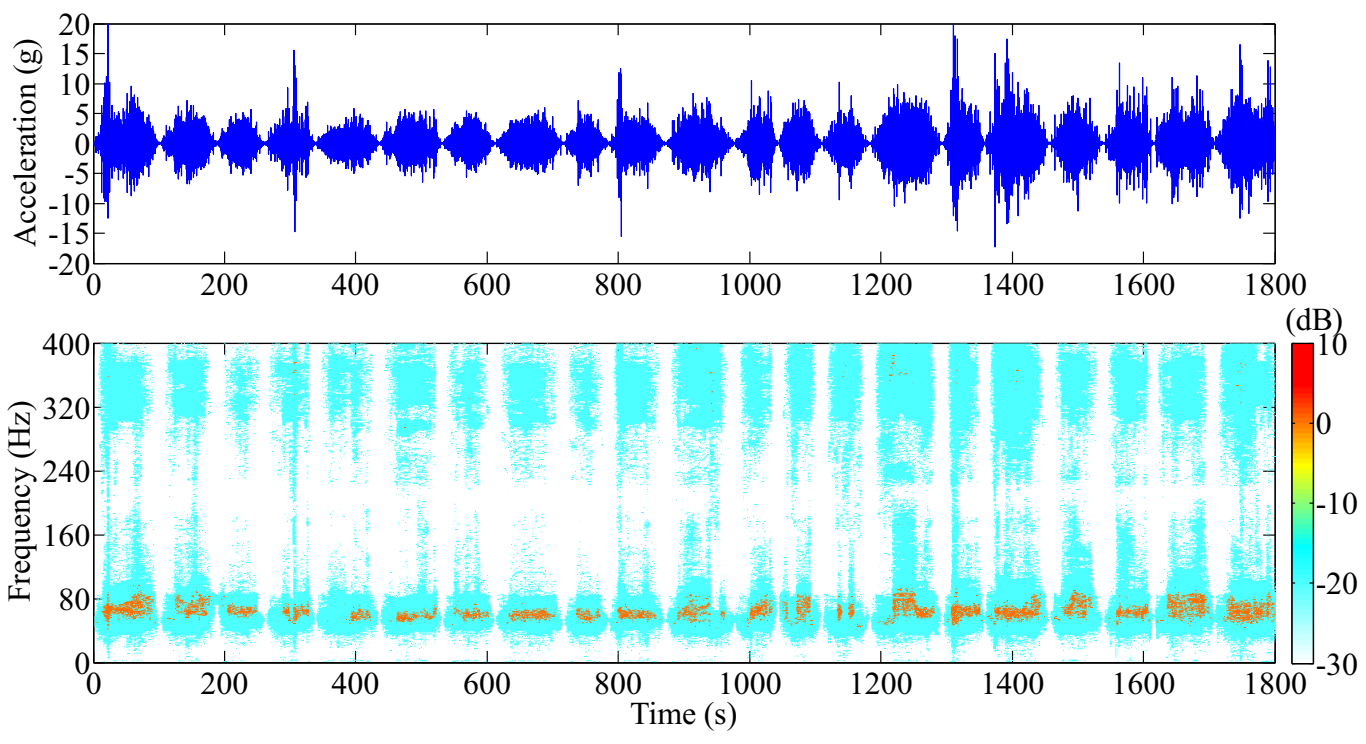

(a)

(b)

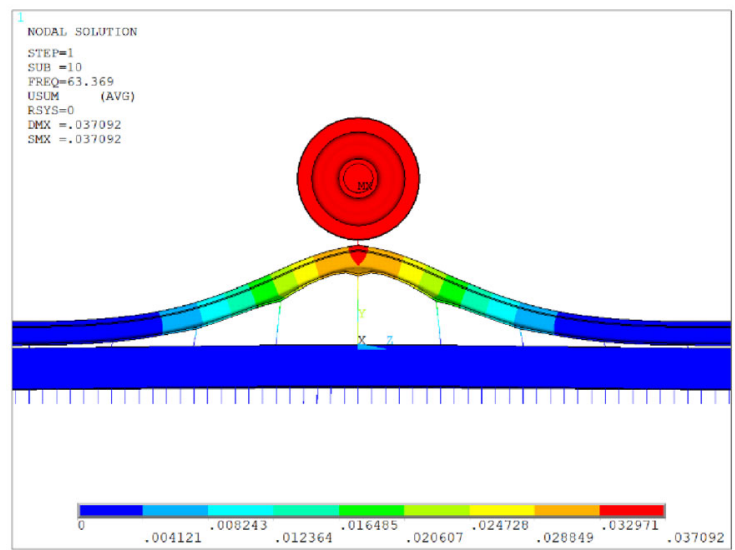

Fig. 15 a Time history and time-frequency spectrum of axle box vertical acceleration of the tested train running on the metro line for a single trip. The dominant frequencies of the axle box vertical acceleration range from 50 to $80 \mathrm{~Hz}$, which are induced by the P2 resonance. b Mode shape of the P2 resonance with frequency of $63 \mathrm{~Hz}$ of monolithic concrete bed with DTVI2 fastener, obtained by finite element analysis

our research team [75]. Through field investigation, Li et al. [17] pointed out that polygonal wear with 7 harmonics in one metro line was also caused by the $\mathrm{P} 2$ resonance. In summary, the P2 resonance is an important frequency-fixing mechanism of low-order wheel OOR. The fluctuation of the vertical force between the wheel and rail resulting from the $\mathrm{P} 2$ resonance is the root cause of wheel OOR. The higher the vertical railway track stiffness, the higher the vertical force amplitudes and the more rapidly polygonal wear will develop [75].

\subsubsection{Frictional self-excited vibration of wheelset-track system}

Chen et al. [76] were the first to study the formation mechanism of wheel polygonisation based on the theory of frictional self-excited vibration of the wheelset-track system. Based on the assumption of the saturation of creep force, a complex eigenvalue analysis of the wheelset-track system was performed using the commercial finite element software ABAQUS. If there is a positive eigenvalue, it is considered as a possible factor to induce polygonal wear, and the frequency-fixing mechanism is the corresponding mode frequency of the wheelset-track system with a positive eigenvalue. The model was further extended to study the reason for the polygonal wear of high-speed train wheels [77, 78]. Moreover, the unstable vibration of the disc brake system of high-speed trains was thought to be a possible cause of wheel polygonisation from the viewpoint of frictional self-excited vibration [79]. However, the precondition of frictional self-excited vibration is that the friction reaches saturation, which is rarely achieved in the actual operation of the train, especially for trains with distributed power and straight lines. In addition, it is 
difficult to test whether the friction self-excited vibration occurs in a field test.

\subsubsection{Lower bending or torsional modes of the wheelset}

The lower bending or torsional modes of the wheelset play an important role in the formation of wheel polygonisation. Morys [20] proposed a numerical model to simulate the enlargement process of wheel OOR on ICE-1 high-speed trains, which consisted of a short-term system dynamics model that considered the flexibility of the wheelset and an iterative long-term wear model. Simulation results indicated that the polygonisation of the wheel with the initial three harmonics developed rapidly without changing its phase, owing to the bending resonance of the wheelset excited by the initial wheel OOR. The lateral slip between the wheel and rail induced by the bending vibration of the wheelset plays a key role in the development of the wheel OOR. Through extensive experiments conducted on site, Jin et al. [80] revealed that the first bending resonance of the wheelset was the root cause of nine orders of polygonal wear of LIM metro train wheels. The authors [16] investigated the formation mechanism of high-order polygonal wear of metro train wheels. The root cause of the highorder wheel polygonal wear was found to be the first bending vibration of the wheelset. The main excitation sources of the first bending vibration of the wheelset were rail corrugation in the 1/3-octave band with centre wavelength $200 \mathrm{~mm}$ on sharp curves (Fig. 16a) and residual high-order wheel polygonal wear after wheel re-profiling (Fig. 16b). When the train is running on sharp curves at a specific speed, rail corrugation or wheel polygon will excite the first bending vibration of the wheelset (Fig. 16c). The wheels mainly vibrate in the lateral direction if the first (a)
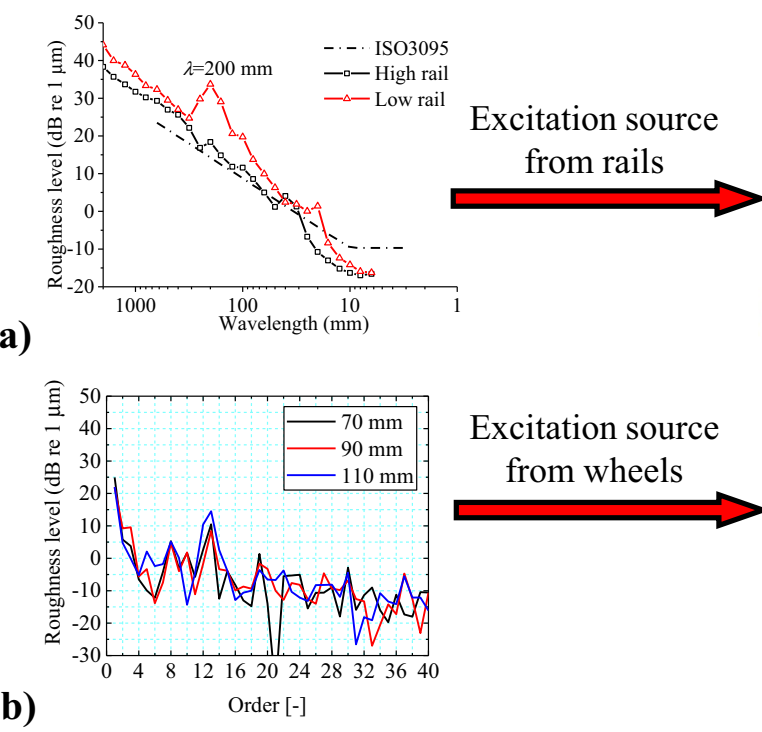

Excitation source from wheels

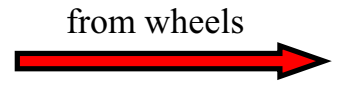

(c)

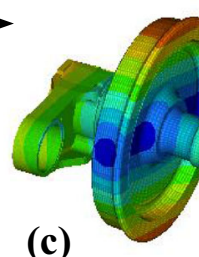

Re-profiling
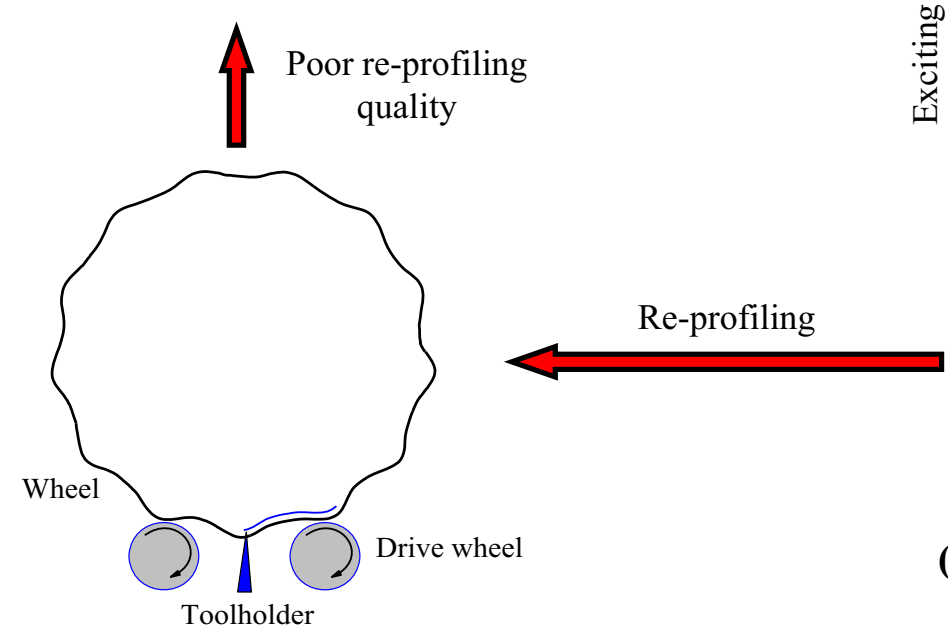

(f)

(e)

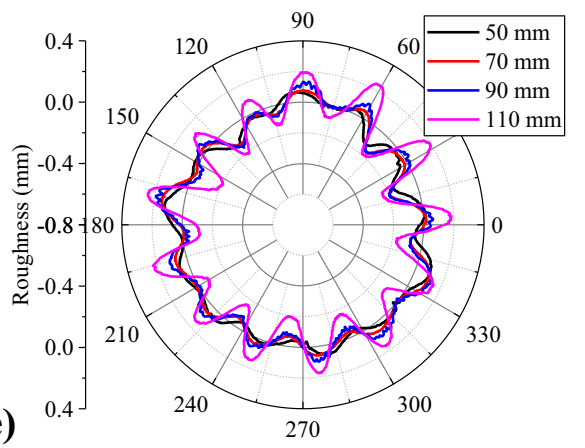

Fig. 16 Formation process of high-order polygonal wear of metro train wheels [16]: a rail corrugation on the low rail of sharp curves; b residual high-order polygonal wear after wheel re-profiling; $\mathbf{c}$ the first bending mode of the wheelset; $\mathbf{d}$ proportion of sharp curves; e serious high-order polygonal wear; and $\mathbf{f}$ wheel re-profiling with underfloor wheel lathe

Rail. Eng. Science (2020) 28(4):317-345 
bending vibration of the wheelset is excited. The lateral slip between the wheels and rails caused by the elastic vibration of the wheelset plays a key role in the formation of high-order polygonal wear.

Generally, the lateral creepage or creep force resulting from the yaw angle of the wheelset on a sharp curve is larger than that on a straight track or a gentle curve, which will further increase the lateral vibration of the wheels and make the wear more serious. The wheel flange comes into contact with the rail side of the high rail when the train runs on sharp curves, which was confirmed by the field observation and rail profile measurement results of the high rail. Therefore, the lateral vibration of the wheels on the high rail was limited by the rail. Moreover, rail corrugation in the 1/3-octave band with centre wavelength $200 \mathrm{~mm}$ mainly occurred on the low rail. All these factors make the polygonal wear of the wheels on the low rail side more serious. Additionally, the proportion of the sharp curves of the left and right hands in the metro line is obviously different (Fig. 16d), which results in more severe polygonal wear of the right wheels than of the left wheels. Wheel re- profiling is the main means by which high-order wheel polygonal wear is controlled at present. However, the reprofiling of the wheel OOR is not of high quality and cannot completely eliminate high-order polygonal wear (Fig. 16f).

The authors [18] reported that two types of freight traffic locomotives exhibited serious wheel OOR, of which the dominant wavelength was $200 \mathrm{~mm}$. The cause was further investigated by Tao et al. [81, 82]. The formation and development of wheel polygonal wear are presented in Fig. 17 and summarized as follows [82]: (1) The first and second bending vibrations of the wheelset, with frequencies $(f)$ of approximately 84 and $120 \mathrm{~Hz}$, respectively, were responsible for the high-order wheel polygonal wear. The resonance frequencies were constant. However, the speed of the locomotive $(v)$ usually varies within a certain range, such as $70-78 \mathrm{~km} / \mathrm{h}$ for freight traffic on the main railway lines. The lower bending vibration of the wheelset can be excited easily during locomotive operation. The wavelength of the wheel polygonisation can be expressed as $\lambda=v / f$, which mainly ranges from 160 to $260 \mathrm{~mm}$. The lower bending vibration of the wheelset was an inherent

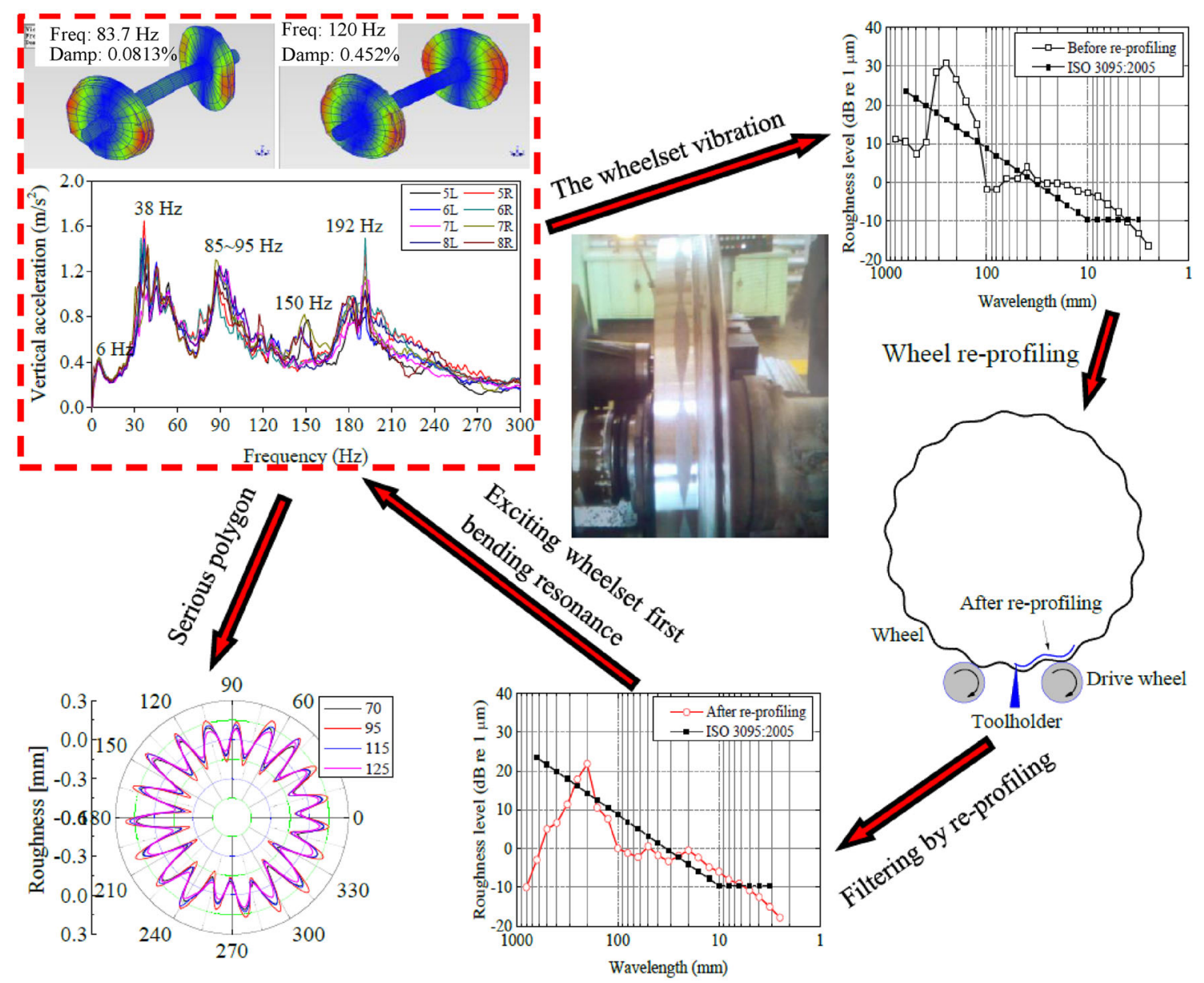

Fig. 17 Formation and development process of high-order polygonal wear of locomotive wheels [82] 
factor of wheel polygons. (2) Wheel OOR occurs at all wheel treads. To recover the desired wheel roundness, the wheels were re-profiled by an underfloor wheel lathe. However, because of the poor repair process of one type of underfloor wheel lathe, the wheel with OOR in the $1 / 3$ octave band with centre wavelength $200 \mathrm{~mm}$ could not be removed. If the wheel exhibits an OOR with a wavelength ranging from 160 to $260 \mathrm{~mm}$, irregular wear with a wavelength of approximately $200 \mathrm{~mm}$ will remain after reprofiling by this type of underfloor wheel lathe. (3) The wheel with remaining OOR with a wavelength of approximately $200 \mathrm{~mm}$ after re-profiling will further excite the first bending vibration of the wheelset. Wheel polygonal wear will develop rapidly with a dominant harmonic order of 18 or 19. Moreover, discrete wheel irregularities, such as wheel flats and long local defects, have some influence on the formation of wheel polygonal wear [83], which can excite the first bending vibration of the wheelset.

Wheel OOR with 20 harmonics occurs on one type of locomotive in South Africa reported by Reitmann et al. [12]. The monitoring of measurement data indicated that the peak-to-peak value of the wheel OOR located on the non-gear side of the axle was much higher than that located on the gear side. The wavelength-fixing mechanism of wheel polygonisation of this type of locomotive was the torsional vibration of the wheelset $[84,85]$. The nodal point of the first torsional mode is not in the centre of the axle; thus, it causes an asymmetrical torsional response, which results in asymmetric polygonal wear. The torsional vibration of the wheelset can be excited by the stick-slip vibration under saturated slipping conditions on a dry rail [84]. Moreover, harmonics and interharmonics resulting from a variable-frequency drive also play an important role in exciting the first torsional resonance of the axle [85].

\subsubsection{Bending vibration modes of the rail or track}

Johansson and Andersson [74] simulated the wear evolution of wheel polygonisation and pointed out that the vertical track anti-resonance at $165 \mathrm{~Hz}$ was the main reason for the increase in wheel OOR with orders 14-20. Wu et al. [86] and Cai et al. [87] studied the formation process of high-order wheel polygonal wear of high-speed trains through simulation and concluded that the third bending vibration mode of the rail segment between two wheels of the same bogie was the primary contributor to the formation of high-order wheel polygonal wear. Dai et al. [88] summarized the wheel polygonisation passing frequencies of different types of high-speed trains running on different types of ballastless tracks in China and found that the passing frequencies mainly depended on the sleeper span and wheelbase of the bogie. The excitation frequency was determined by simulation and laboratory tests. The results showed that the frequency of the third bending vibration mode was consistent with the passing frequency of wheel polygonal wear, which was the main reason for the formation of high-order polygonal wear. However, whether the third bending mode of the rail between two wheelsets of the bogie can be excited in the running state of the vehicle remains to be verified. Qu et al. [89] also believed that the rail local vibration mode (modal frequency is $591 \mathrm{~Hz}$ ) between two wheelsets of the same bogie can be one possible mechanism of high-order wheel polygonisation of high-speed train in China through field experiment.

\subsubsection{Excited resonance of the bogie}

The authors' research team presented a detailed investigation of the mechanism of high-order wheel polygonal wear of a new type of high-speed train in China through scientific field experiments [90]. The important results are shown in Fig. 18. It was found that almost all the wheels exhibited 23 harmonics (Fig. 18a). To determine the key frequencies related to wheel polygonal wear, the vibration and dynamic characteristics of vehicle and track were tested. It was found that the vibration isolation of the bogie system was weak near $600 \mathrm{~Hz}$, and there was a coupled vibration between the wheelset and bogie frame (Fig. 18b). Through modal analysis, it was found that there are eigenmodes near this frequency for both the wheelset (Fig. 18c) and bogie frame (Fig. 18d). The investigation results indicated that the excited resonance of the bogie frame was responsible for the formation of high-order polygonal wear. Furthermore, the operating speed played a key role in the formation process of high-order polygonal wear. High-order polygonal wear can be effectively suppressed by operating the train at variable speed, which has been verified by field practice. Guo et al. [91] found that the bogie system has an eigenfrequency of approximately $580 \mathrm{~Hz}$ through a high-frequency modal test of the bogie, and the damping ratio is very low. The vibration of this mode easily causes the high-speed train wheels to form an 18th-19th-order polygon.

\subsubsection{Vibration of other components of the bogie}

Ma et al. [92] studied the formation of ninth-order polygonal wear of LIM vehicle wheels and proposed that the wheel polygonisation was induced by the vertical vibration of the LIM. Liu et al. [93] also studied the causes of ninth-order polygonal wear of an LIM vehicle. It was believed that the coupled vibration of the bending mode of the wheelset and vertical vibration of the LIM resulted in wheel polygonisation. Fu et al. [94] simulated and analysed the causes of wheel polygonal wear with 8-9 harmonics of an LIM vehicle. They suggested that the formation of the wheel 


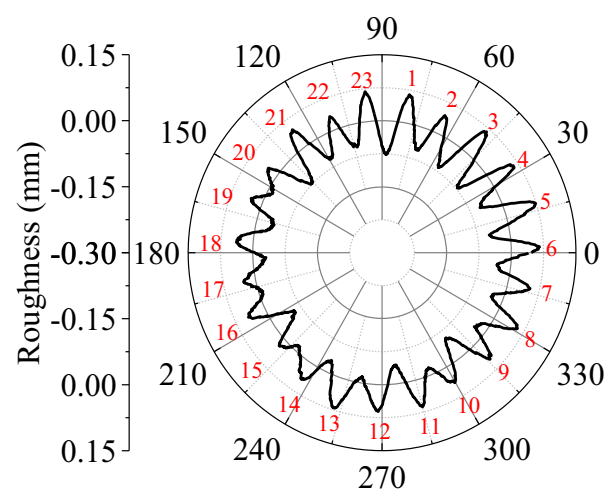

(a)

(c)

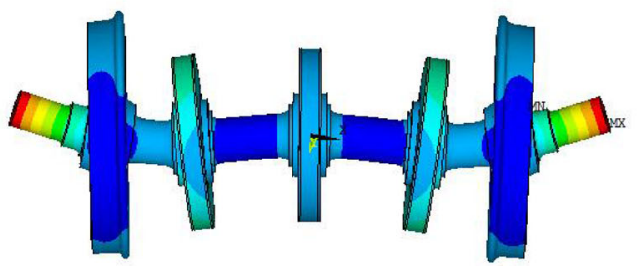

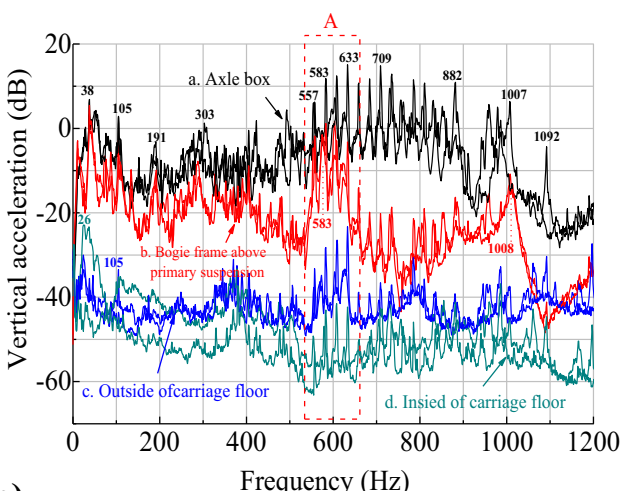

(b)

(d)

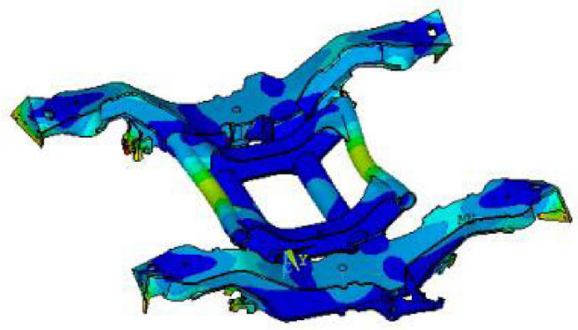

Fig. 18 Causes of wheel polygonal wear of one type of high-speed train [90]: a typical measurement result of wheel polygonal wear; $\mathbf{b}$ vibration feature of the axle box, bogie frame, and car body; ceigenmode of the wheelset $(589 \mathrm{~Hz})$; and d the eigenmode of the bogie frame $(601 \mathrm{~Hz})$ related to the formation of wheel polygonal wear based on the frequency-fixing mechanism

polygonisation comprised two stages. First, the residual polygonal wear with four harmonics after wheel re-profiling under the normal running speed of the vehicle $(85 \mathrm{~km} / \mathrm{h})$ excited vertical vibration of the LIM, which led to the evolution of the fourth-order polygon into that of 8th-9th order. Then, wheel polygonal wear with 8-9 harmonics excited the first bending vibration of the wheelset at the normal running speed of the vehicle, which maintains a constant phase of wheel polygonal wear during the evolution and then causes further deterioration of the wheel polygonal wear with 8-9 harmonics.

\subsection{Induced by thermoelastic instability}

In the late twentieth century, wheel corrugation was very common on trains equipped with cast-iron blocks. However, the wheel roughness level and emitted noise level of the vehicles equipped with disc brakes were much lower than those of vehicles equipped with cast-iron blocks, which indicated that tread braking played a vital role in wheel roughness. Nielsen et al. [5] summarized the cause of wheel corrugation due to tread braking and pointed out that thermoelastic instability between the cast-iron blocks and wheel tread during braking was the main reason [95, 96], but the wavelength-fixing mechanism of this type of wheel corrugation is still unclear. According to the authors' investigation of metro lines in China in 2015, wheel corrugation was found only on one line (see Fig. 3). In the initial operation phase, the type-B train equipped with tread brakes using the repair compound brake block ran on the line with a maximum operating speed of $80 \mathrm{~km} / \mathrm{h}$. Wheel corrugation with a wavelength of $30 \mathrm{~mm}$ appeared around the tread circumference after an operating mileage of $10,000 \mathrm{~km}$. At that time, the vehicle manufacturer suspected that the cause of wheel corrugation was the application of the repair compound brake block, which has an iron insert. The iron insert is set along the lateral direction in the middle of the brake block with the original intention of reducing the thermal damage and roughness of the wheel. Based on the suspicion of the cause, the repair compound brake block was replaced with a common compound brake block that had no iron insert by the metro operation company. After the replacement of the brake block, the wheel corrugation disappeared. However, the generation mechanism of wheel corrugation is still an open question.

\section{Simulation of the wheel polygonisation evolution}

Wheel polygonisation is a very complex phenomenon. Many influencing factors cannot be easily identified through experimental research. Therefore, it is necessary to study this problem through theoretical analysis and numerical simulation. The numerical simulation of wheel 


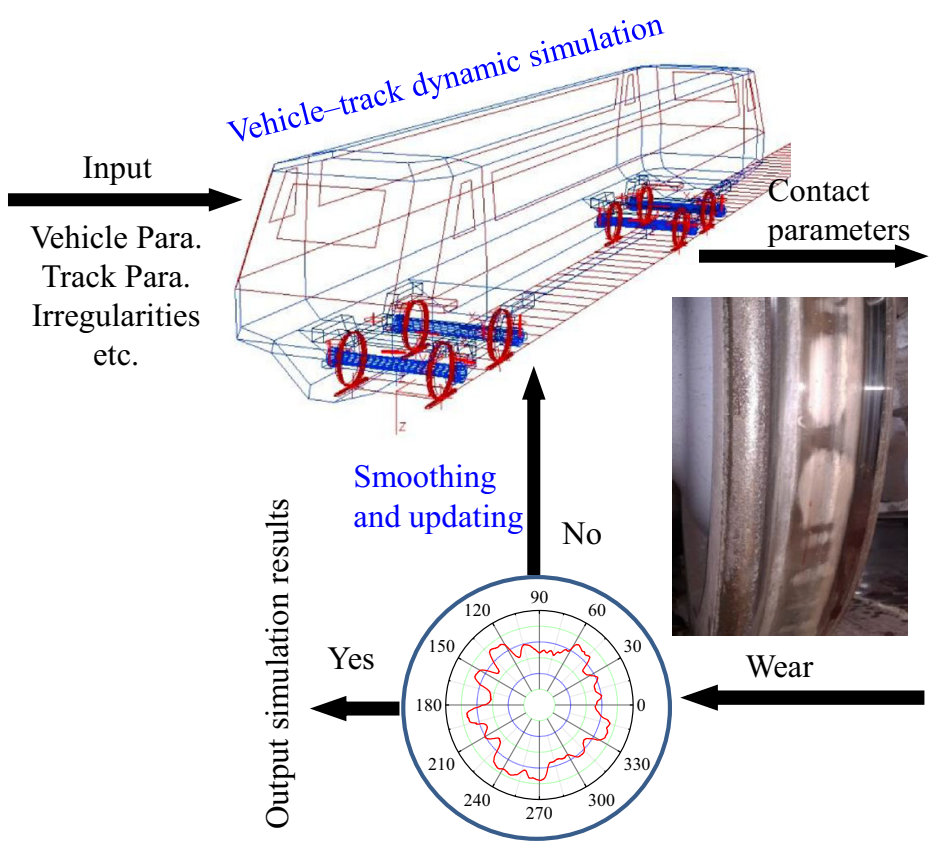

Local wheel-rail contact
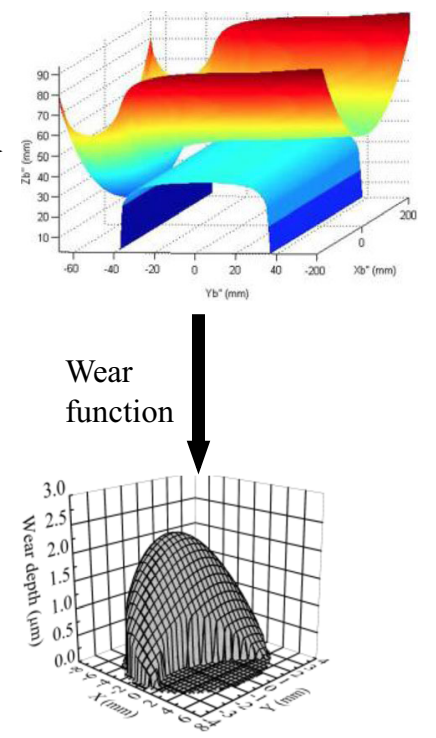

Wear calculation

Fig. 19 General architecture of wheel polygonisation simulation

wear usually includes two main modules, that is, vehicletrack dynamics simulation and wheel wear calculation. Different research problems suggest that the vehicle-track dynamics simulation model and wheel wear calculation model have different emphases. A general flowchart of the numerical simulation of wheel polygonal wear is shown in Fig. 19. First, according to the research object, the corresponding vehicle-track dynamics simulation model is established. The vehicle parameters, track parameters, wheel and rail irregularities, vehicle operation parameters, and vehicle control parameters are used as input for the vehicle-track dynamics simulation. Second, the global contact parameters (such as the wheel-rail normal force, creepage, and contact point position) obtained from the vehicle-track dynamics simulation are used as the input for the wheel-rail local contact calculation. The tangential stress distribution and creep distribution within the contact patch are calculated. Kalker simplified theory (FASTSIM algorithm) and its revisions are commonly used in wheelrail local contact calculation. Then, the wheel-rail local contact parameters calculated by the local contact model are used as the input for the wheel wear calculation. The wear model mainly includes the Archard wear model or a wear function based on the frictional work. Finally, the wear in the contact patch is superposed along the longitudinal direction to obtain the wear on each cross section of the wheel. The wear on each cross section is extracted to obtain the roughness of the wheel circumference. If the simulation reaches the set termination condition (usually using the vehicle running mileage or the number of iterations), the final simulation result of the wheel OOR is output. Otherwise, the wheel roughness is returned to the dynamic simulation model after being filtered and smoothened.

Many researchers have carried out wheel polygonal wear simulation research based on the above simulation process. Soua et al. [97] were one of the first scholars to study wheel polygonal wear by means of wheel wear simulation. Subsequently, Brommund [98], Meywerk [99], Morys [20], and Meinke [68] studied the evolution process and influencing factors of wheel polygonal wear by means of simulation.

In the twentieth century, because of the limitations of the computer processing capability and the imperfection of the wheel wear model, many researchers could only use some simple dynamic models combined with frictional work to simulate wheel polygonal wear. In the twenty-first century, with the improvement of computer capacity, vehicle-track coupled dynamics theory [100], and material wear research, more complex and enhanced models have been developed and used to study wheel polygonal wear. A state-of-the-art review of the modelling of dynamic traintrack interaction in conjunction with the prediction of irregular wear can be seen in Ref. [5] published by Nielsen et al.

Johansson and Andersson [74] established a wheel polygonal wear simulation model considering wheel-rail three-dimensional dynamic interaction and wear 
prediction. To consider the effect of the high-frequency vibration of the track, the rails were modelled with the Timoshenko beam. However, the vehicle model was relatively simple. Only a three-dimensional bogie model was considered, and all components of the bogie were simulated as rigid bodies. The wheel-rail dynamic interaction was simulated by combining the Hertzian theory and ShenHedrick-Elkins theory. The classic Archard wear model was used in the wheel wear calculation. The prediction of wheel polygonal wear was realized through iterative updating of the wheel wear. Later, most of the wheel polygonal wear simulation research has been based on the idea of Johansson and Anderson [74]. For example, Wu et al. [86] and Cai et al. [87] carried out polygonal wear simulation of high-speed railway wheels, and a simulation study on the low-order polygonal wear of metro train wheels was conducted by Cai et al. [75] and Fu et al. [94]. Research on polygonal wear simulation of locomotive wheel was performed by Tao et al. [83], while Peng et al. $[101,102]$ investigated the influence of wheelset flexibility, material friction and wear models on wheel polygonal wear. Ye et al. [104] studied the influence of wagon wheel flat on wheel polygonisation development.

Although many researchers have studied the evolution of wheel polygonisation by simulation, the wheel polygonisation simulation involves many aspects of knowledge, and many factors have a greater impact on the results of wheel polygonal wear simulation. Fu et al. [94] found that the smoothing of the wheel polygonal wear profile has a significant influence on the simulation results. When the smoothing method is not reasonable, it can cause a discontinuity in wheel polygonal wear along the wheel circumference, which can lead to abnormal impact vibration in the dynamic simulation. In addition, the scale of wheel polygonal wear updating also has a great influence on the simulation results, so it is necessary to select an appropriate updating scale according to the actual simulation situation. Peng et al. [102] studied the influence of wear models presented by Pearce and Sherratt [105], Jendel [106], Lewis et al. [107], and Zobory [108] on the prediction of wheel polygonal wear. It was found that these models can predict the same wheel polygon features, but the polygonal wear amplitudes predicted by different wear models have some difference. In Ref. [102], both global and local methods were considered to apply wear models. For the global method, the contact parameters were studied on the whole wheel-rail contact patch, considering the global forces/ creepages, i.e. the global longitudinal tangential force, the global lateral tangential force, the global spin torque, and the global longitudinal creepage, the global lateral creepage, and the global spin. For the local method, the contact problem is studied by dividing the wheel-rail contact patch into small elements and calculating the contact parameters individually for each one. It was concluded that the global method is not suitable for polygonal wear simulation. The research results of Fu et al. [94] and Peng et al. [102] provide a good reference for the selection of wear model, profile smoothing method, and updating scale in the prediction of wheel polygonal wear. Peng et al. [103] proposed an instantaneous wear frequency response function to evaluate the evolution tendency of wheel OOR. They found that except for the amplitude-frequency characteristics, the phase-frequency characteristics are very important for the formation of wheel polygonisation. If the phase between the instantaneous wear depth and the initial OOR is within $90^{\circ}-270^{\circ}$ range, the initial OOR will grow.

The formation process of wheel polygonal wear, especially high-order polygonal wear, is very intricate. It is difficult to accurately reproduce the development process of wheel polygonal wear through simulation. In the study of high-order polygonal wear, the mid-high-frequency elastic vibration of the vehicle and track structure should be considered as well as the influence of mid-high-frequency elastic vibration of wheel-rail on the wheel-rail dynamic interaction. In addition, some problems should be clarified. For instance, how the wheel polygonal wear accumulates in the development process; under what conditions can the valley wear be accelerated, while the crest wear becomes slower, and whether the phase of the wear is fixed or variable in the formation process of the polygon needs to be further revealed.

Wheel OOR simulation is a very difficult task. Many factors, especially for contact model and dynamics model, have great influence on wheel OOR simulation. The contact model and dynamics model are quite important, which should have higher calculation efficiency to meet the simulation requirements of long-term wear prediction. It is of importance to employ appropriate wheel-rail contact model. The Hertz theory and FASTSIM are widely used to solve the normal and tangential contact, respectively. However, the Hertz hypothesis is invalid in some special cases, for example for wheel corrugation of which the wavelength is very close to the contact patch. Thus, nonHertzian normal contact model combined with non-steady tangential contact model is a good choice. The wheel-rail contact model generally does not change the order (or frequency) feature of the predicted wheel OOR, but it can influence the development of wheel roughness level. FASTSIM is sufficient in most cases. However, if traction or braking is taken into account, the modified FASTSIM proposed by Spiryagin et al. [109] is alternative, which is more suitable for traction or braking conditions than the original FASTSIM. Non-steady contact model, even nonHertzian and non-steady contact model, was used to predict rail corrugation by some researchers, such as Knothe and Groß-thebing [110], Baeza et al. [111], Vila et al. [112], 
and Torstensson et al. [113]. However, it is not used to predict wheel roughness in published papers. Whether it is necessary to use this method to predict wheel roughness is worth exploring.

As summarized in Sect. 4, many types of wheel polygonisation are induced by the natural vibration of vehicletrack system. The dynamics model should have the ability to reflect the vibration behaviour of the vehicle-track system and to cover the frequencies excited by wheel polygon. The flexible vibration of vehicle-track system, especially the flexibility of the wheelset and rail, should be considered. Moreover, it is necessary to validate the dynamics model by test results. The authors' research team has done some simulation work in wheel polygonal wear, see Refs. [15, 75, 83, 86, 87]. In Ref. [75], we built a wheel polygonal wear model considering a vehicle-track coupled dynamics model and a long-term wear model. In the dynamics model, the flexibilities of the wheelsets and track (rails and monolithic concrete bed track) were considered. The FRFs of the track system and the accelerations of the axle box were validated firstly. Taking the initial wheel irregularities measured after wheel re-profiling as input, the evolution of wheel polygonisation was carried out. The simulation results could reflect the features and evolution process of wheel polygonisation and were in good agreement with the measurement results. In Ref. [83], a similar model was used to simulate the effect of discrete wheel defects on the formation of wheel polygonisaiton. The features of wheel polygonisation obtained by simulation were also consistent with the measurement ones.

For wheel OOR simulation, the authors have some experiences: (1) In order to speed up the simulation efficiency, the lateral wear of wheels can be ignored when only wheel OOR is simulated. (2) Before each dynamic simulation, the wheelset is rotated through a random angle to avoid the coincidence of wheel and track excitations. (3) There is no essential difference between the existing wear models, but the selection of wear coefficient has a great influence on the development of wheel OOR. The wear coefficient can be adjusted according to the measured wheel OOR. (4) Choosing a good smoothing method is

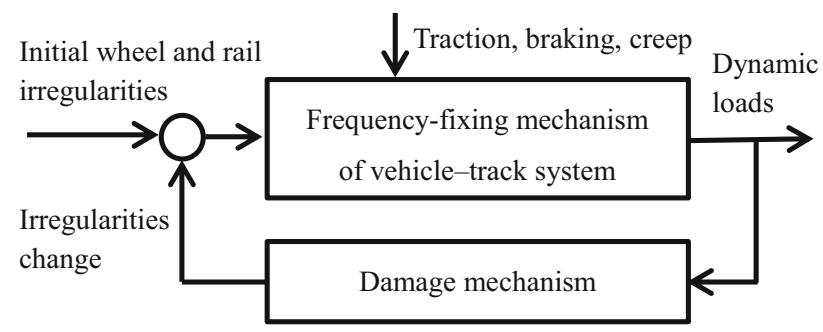

Fig. 20 Formation process of wheel polygonal wear (modified after [73]) very important. In Ref. [94], the smoothing method is recommended.

\section{Countermeasures}

The formation mechanism of wheel polygonal wear is very complex. When the formation mechanism and key influencing factors of wheel polygonal wear are fully revealed, corresponding measures can be taken, which is obviously the most ideal. It can be seen from the literature review in Sect. 4 that the wheel OOR, especially the wheel polygonal wear, is usually caused by an inherent vibration of the vehicle-track system. As with rail corrugation [73], the formation process of wheel polygonal wear can be represented by the feedback process shown in Fig. 20; that is, the formation mechanism of wheel polygons includes the frequency-fixing mechanism and damage mechanism (usually wear). Before the railway line is opened, the wheel-rail surface is not absolutely smooth. There are initial irregularities (such as the wheel's geometry or mass eccentricity or rail welding joint irregularity). The initial irregularities of wheel and rail, as well as other factors such as traction and braking forces, and creep between wheel and rail, can lead to the dynamic wheel-rail contact force, creepage, creep force, and contact patch size. The initial wheel irregularities can be changed through wear damage. The change in wheel irregularities, in turn, will affect the dynamic interaction of the vehicle-track system, which could gradually show that the contact force and frictional work between the wheel and rail interface are more prominent at a specific frequency. For a specific speed, this means that the wheel wear is more significant at a specific wavelength. Therefore, to control the formation and development of wheel polygonal wear, it can be considered from two aspects: frequency-fixing mechanism and damage mechanism, including (1) controlling the excitation sources of the wheel and rail, (2) avoiding or restraining the inherent vibration related to the formation of wheel polygonal wear in the vehicle-track system, and (3) reducing wheel wear. A summary of wheel polygonal wear mitigation measures is shown in Table 2. Obviously, it is difficult or even impossible to change the vibration characteristics of the vehicle-track system for railway lines or vehicles that have been put into operation. Therefore, it is feasible to adopt some passive measures to control the wheel polygonal wear, among which wheel re-profiling is one of the most commonly used strategies. In addition, the field application experience in China shows that the reasonable use of brake shoes or tread cleaners also has a positive effect on controlling wheel polygonal wear. 


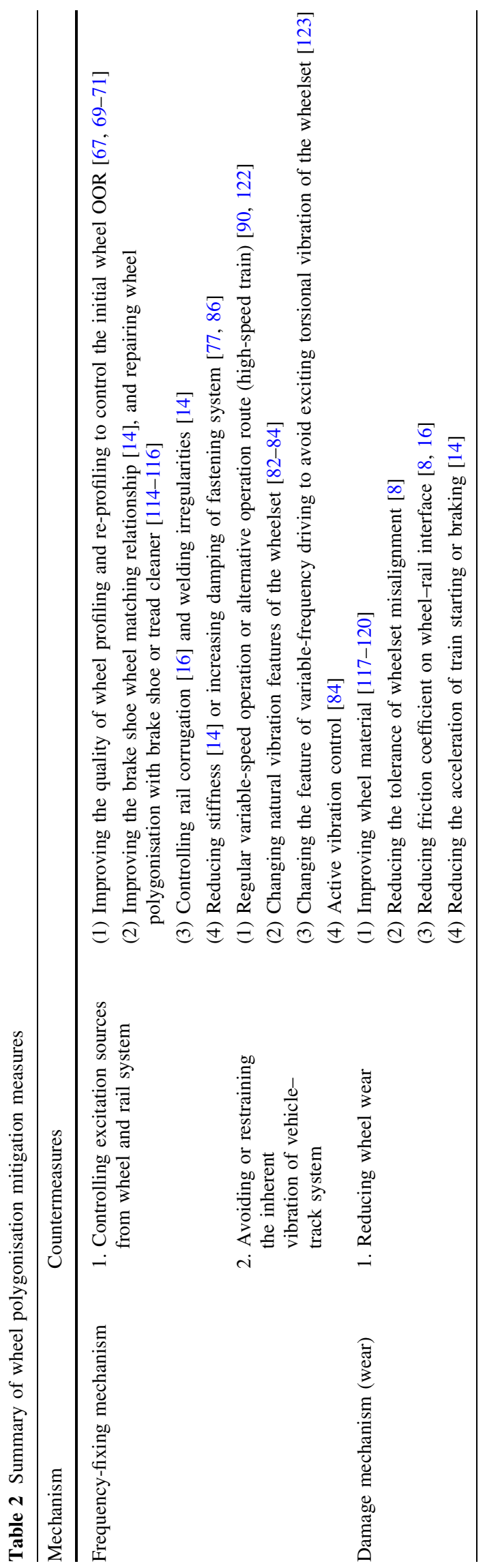

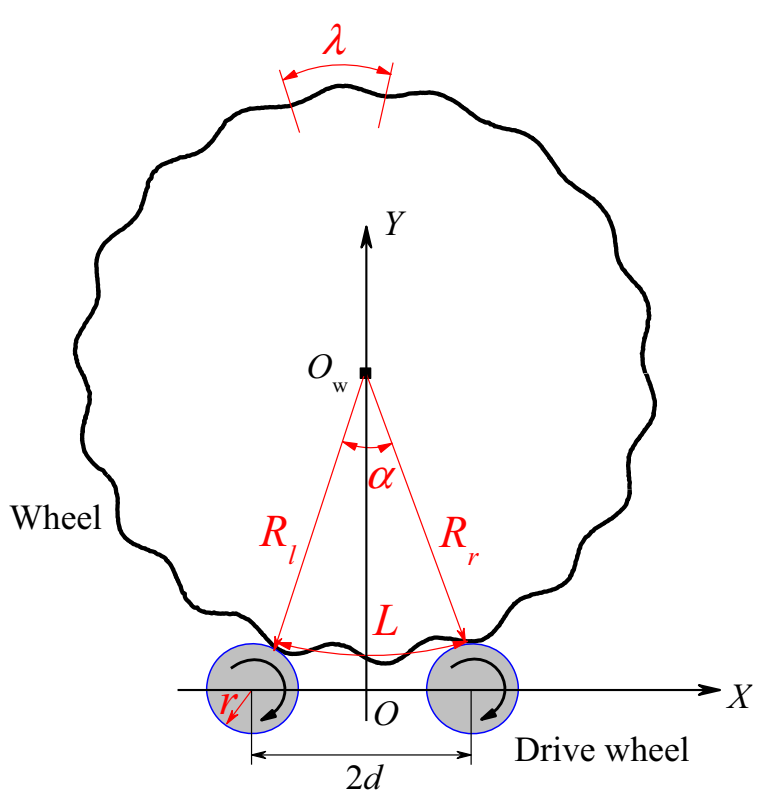

Fig. 21 Geometric relationship between the polygonised wheel and drive wheels of the underfloor wheel lathe [82]

\subsection{Improving wheel re-profiling quality}

In the process of wheel re-profiling, there are many process parameters and structural characteristics of the underfloor wheel lathe that could affect the quality of wheel re-profiling. In an investigation of polygonal wear of locomotive wheels, the authors [18] found that an underfloor wheel lathe with tread positioning is widely used in locomotive depots, where the wheels suffered from severe polygonal wear. The re-profiling quality of the underfloor wheel lathe with axle box positioning was much better than that with tread positioning. If the wheel retains obvious polygonal wear after re-profiling, it will lead to the rapid development of polygonal wear. In addition, the distance between the driving wheels of the underfloor wheel lathe has a significant influence on the quality of wheel re-profiling, as shown in Fig. 21. When the wheel arc length (denoted by $L$ in Fig. 21) between the two supporting points of the driving wheels of the lathe contacting the wheel is about an integral multiple of the wavelength of wheel polygonal wear (denoted by $\lambda$ in Fig. 21), a serious profiling phenomenon will occur in the wheel re-profiling, resulting in the failure to effectively remove polygonal wear. A detailed analysis can be found in Ref. [82]. Ren et al. [69] and Cui et al. [70] reproduced this phenomenon through simulation and proposed that if the distance between the driving wheels of the lathe can be adjusted to an appropriate value according to the wavelength of polygonal wear, the quality would be significantly improved. The authors [16] investigated the re-profiling quality of wheel 

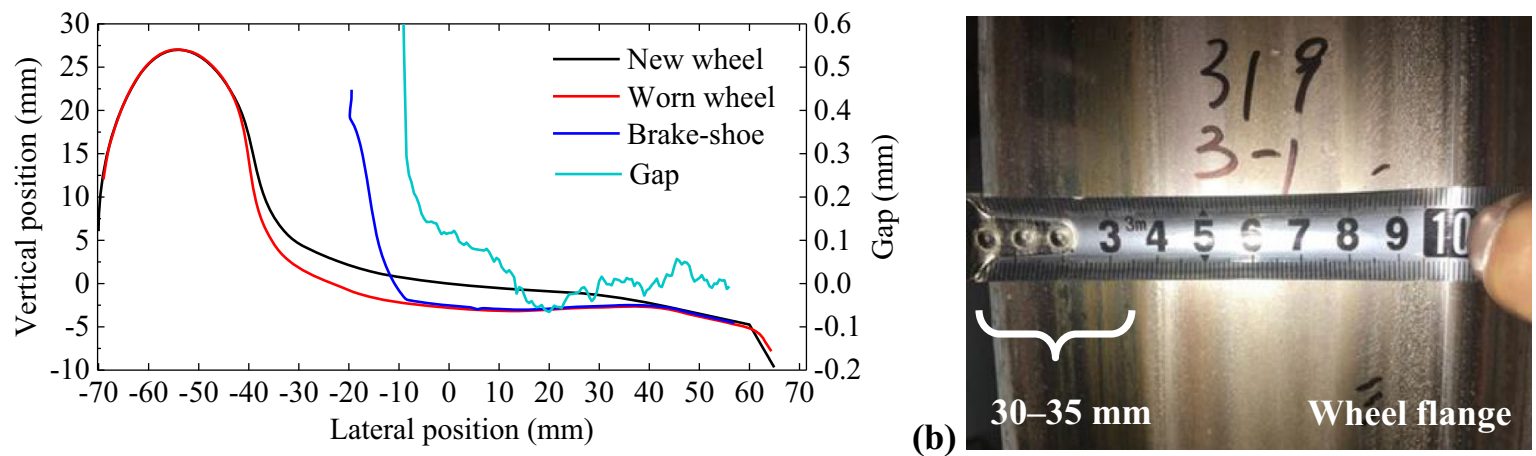

(a)

(b)

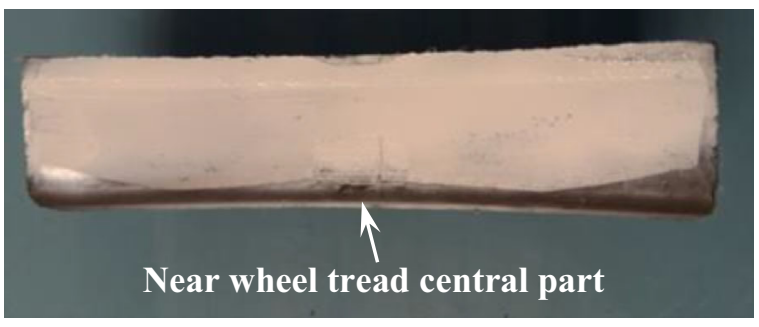

(d)

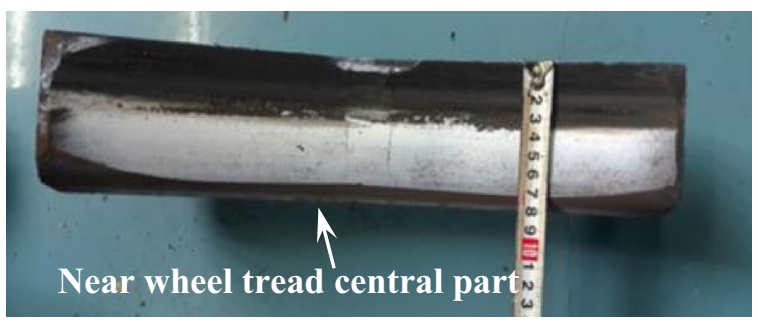

Fig. 22 a Matching relationship between brake shoe and wheel tread, b photograph of wheel tread, $\mathbf{c}$ photograph of brake shoe sprayed with white paint before test, and $\mathbf{d}$ photograph of brake shoe after test [14]

polygonal wear by setting three re-profiling schemes and found that the re-profiling quality of wheel polygonal wear could be significantly improved by increasing the machining times every re-profiling and reducing the turning speed. In addition, Cui et al. [70] and Su et al. [71] found that the eccentricity of the driving wheel of an underfloor wheel lathe can also cause low-order wheel OOR during re-profiling.

In summary, for wheels with polygonal wear, the wheel re-profiling quality can be effectively improved by using the underfloor wheel lathe with axle box positioning, increasing the amount of turning and machining times, reducing the turning speed, and adjusting the distance between the driving wheels according to the wavelength of wheel polygonal wear. In addition, controlling the eccentricity of the driving wheel of the underfloor wheel lathe can effectively avoid the low-order wheel OOR caused by the re-profiling.

\subsection{Repairing wheel polygonisation with brake shoe or tread cleaner}

Wheel-tread brakes are widely used in the pneumatic brakes of trains with speeds less than $80 \mathrm{~km} / \mathrm{h}$, whereas the disc brake is used primarily in the air brakes of trains with speeds greater than $80 \mathrm{~km} / \mathrm{h}$. To ensure the cleanliness of the wheel tread and improve the wheel-rail adhesion, many types of trains are equipped with a tread cleaner. Although the original purpose of the brake shoe or tread cleaner is not to repair wheel OOR, it has been found that they have a significant effect on wheel OOR repair in practical applications in China [114-116]. The best use of brake shoes or tread cleaners to repair wheel OOR depends mainly on the present application experience. If the brake shoe or tread cleaner does not match the wheel tread well, it could lose the function to repair wheel OOR [14], as shown in Fig. 22. The brake shoe cannot contact the wheel tread part near the nominal rolling circle during operation, as shown in Fig. 22d. This disables the function of the brake shoe to repair the wheel OOR near the nominal rolling circle. In addition, when the brake shoe or tread cleaner contacts the wheel, if the applied pressure is too small or the action time is too short, it cannot play a better role in repairing wheel OOR. On the contrary, if the applied pressure is too large or the acting time is too long, it could increase the wear of the wheel and brake shoe or tread cleaner and increase unnecessary operation and maintenance costs. Therefore, it is necessary to adjust the control parameters and logic according to the actual application. At the same time, it is recommended to install tread cleaners on trains equipped with disc brakes. In addition, for trains with tread braking mode, electric braking has basically met the braking demand of the train. The tread braking only works in the low-speed (usually less than $8 \mathrm{~km} / \mathrm{h}$ ) stage of the metro train. Because of the low speed of vehicles and the short acting time of the brake shoe when entering the station, the capacity of brake shoe repair may be limited. Thus, it is suggested to increase the control mode of the tread cleaning brake to improve the repair function of the brake shoe. The existing application experience in some metro lines in 

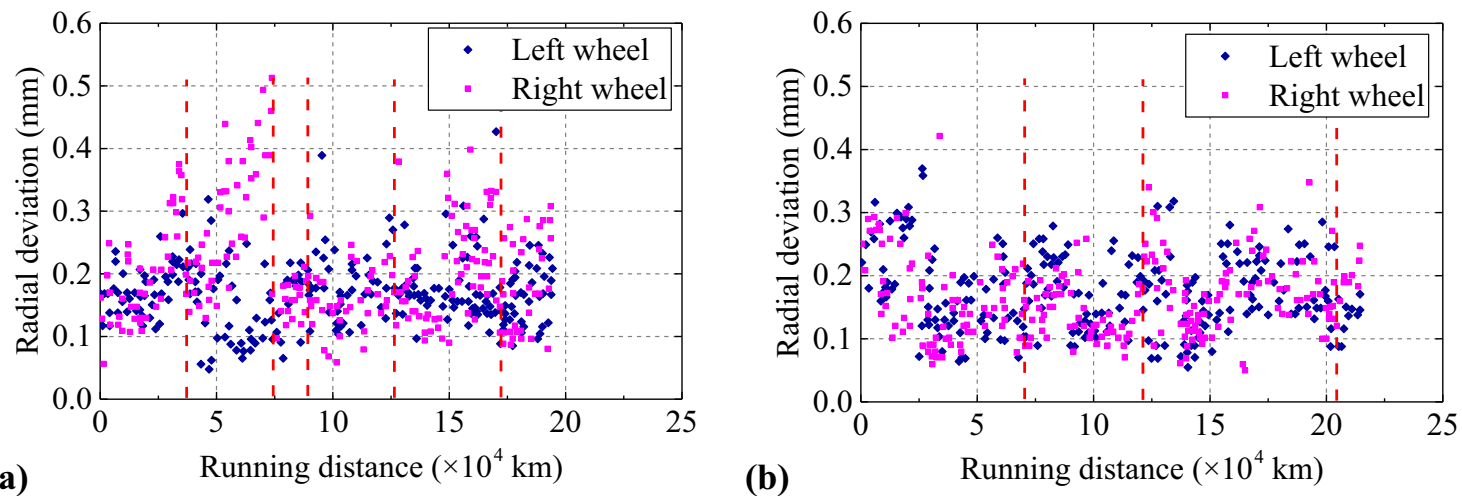

Fig. 23 Development of wheel OOR [117] for a ER7 and b C64M wheels. Dashed lines indicate wheel re-profiling

China shows that the roundness of the wheels has significantly improved by using tread cleaning.

\subsection{Improving wheel material}

Mädler et al. [117] reported a successful application case in which the wheel OOR could be effectively improved by improving the wheel material. In the 1990s, the wheel OOR problem occurred frequently in German high-speed trains, but it did not occur in Japanese Shinkansen highspeed trains at the same time. By comparing the ER7 and C64M wheel materials used in Germany and Japan, it was found that $\mathrm{C} 64 \mathrm{M}$ wheel materials have higher carbon content and higher wheel hardness. DB Systemtechnik studied the wear and fatigue properties of C64M wheel materials with a full-scale wheelset rolling test bench and found that the service life of the C64M wheel was twice more than that of the ER7 wheel, and the wheel did not suffer from OOR problems [117]. On the basis of the above test results, DB AG carried out a small batch of on-track tests with C64M wheels in ICE1 trains. The test results showed that the re-profiling frequency of the C64M wheel was almost $1 / 3$ of the ER7 wheel, and the wheel average service life was at least $40 \%$ longer than that of the ER7 wheel. It is efficient to avoid wheel OOR by using wheel steel with a higher hardness, as shown in Fig. 23. Owing to the excellent performance of C64M wheels, nearly half of the ICE1 and ICE2 train wheels in DB AG had been replaced by C64M wheels by 2012 . Relevant research has also been carried out in China. Chang et al. [118] studied the influence of hardness matching of wheel-rail materials on wheel polygonal wear by using a small-scale wear test machine. It was found that when the hardness ratio of the wheel to rail materials was greater than 1.36 , the polygonal wear of the wheel material samples hardly occurred. The application experience of China's high-speed railway also shows that increasing the hardness of the wheel tread can reduce the occurrence of wheel polygonal wear [119, 120].
Therefore, increasing the hardness of the wheel material can effectively mitigate the formation of wheel polygon wear. Based on bench test and field test, it found that the higher-hardness wheel steel does not harm the rail [117, 121].

\subsection{Other measures}

In addition to the three measures mentioned above, Nielsen et al. [5] also made a relevant summary of other measures to reduce the polygonal wear of wheels, including (1) reducing the wheel-rail vertical force by reducing the unsprung mass and the vertical stiffness of the track, and (2) reducing the tangential wheel-rail contact forces by altering wheel-rail friction and introduction of wheelsets with radial steering. Obviously, the above measures are universal for the wheel polygonal wear of any vehicle type.

The formation of wheel polygonal wear is usually explained by a frequency-fixing mechanism; that is, there is a certain natural vibration mode in the vehicle-track system. When the train is running at a specific speed within a certain range, it will cause the natural vibration of the system under the external excitation and finally wheel polygonal wear. Changing the natural vibration mode of the system is almost impossible, but adjusting the train speed and controlling the external excitation are feasible. $\mathrm{Wu}$ et al. [90] found that wheel polygonal wear is not easy to form during long-term operation with uniform speed for high-speed trains, whereas regular variable-speed operation cannot easily cause polygonal wear. In addition, the field application experience in China shows that the formation and development of wheel polygonal wear can also be effectively controlled for high-speed trains using alternative operation routes [122]. Spangenberg [85] found that variable-frequency drive harmonics and interharmonics can excite axle torsional vibration, which could result in railway wheel polygonisation. Spangenberg and Fröhling 
[123] suggested a solution to solve it by reducing variablefrequency drive interharmonics.

\section{Concluding remarks and outlooks}

The problem of polygonal wear of railway train wheels generally exists in railway field. There are various types of wheel OOR, and the effect of each type on the vehicletrack system is different. Wheel polygonisation as one of wheel OOR has the greatest influence on the vehicle-track system, which is most concerned by researchers, vehicle manufacturers, and railway transportation departments.

The periodic wheel defects, such as wheel polygonal wear and wheel corrugation, reported in the literature is summarized in this paper. The effects of wheel polygonisation on wheel-rail interaction, noise and vibration, and fatigue reliability of vehicle and track components have been reviewed. Wheel polygonisation can cause severe fluctuations in the wheel-rail contact forces, which produce vibrations on the vehicle and track components, such as the wheelsets and rails. Wheel polygonisation also leads to considerable noise emission from the wheel-rail system, which considerably increases the interior and exterior noise of the train. Moreover, wheel polygonisation is an important excitation source that induces abnormal vibrations of the vehicle and track, and it can reduce the fatigue reliability of the vehicle and track components as well as ride comfort.

The formation mechanisms of wheel polygonisation that have been proposed based on either experiment or simulation have been summarized, and it was found that initial wheel defects, a natural vibration of the vehicle-track system, and a thermoelastic instability between the brake shoe and wheel during tread braking can cause wheel polygon or corrugation. Although many efforts have been made to better understand the formation mechanism of wheel polygonal wear, the formation mechanism of polygonal wear of high-speed train wheels in China is still not clearly understood. However, there are three viewpoints to explain the cause of wheel polygonal wear, including an excited resonance of the bogie [90, 91], a bending vibration of the rail [86-89], and frictional selfexcited vibration of the wheelset-track system [77-79]. Although the formation mechanism is not clear, the development of wheel polygonal wear is well controlled by using a tread cleaner, especially the new-generation highspeed EMU of the Fuxing series. There is almost no wheel polygonal wear on this new high-speed EMU.

Although much research has been carried out on wheel polygonal wear, there are many aspects on which further research should be focused:
(1) Reproducing the wheel polygonal wear in the laboratory. At present, there are few literature reports of related research [124, 125]. After the wheel polygonal wear has been reproduced, different wheel-rail contact parameters can be accurately controlled to identify the most critical parameters affecting the wheel polygonal wear. The wheel-rail rolling bench test is usually realized by twin-disc rolling, where the track is simulated by the roller. Although the track parametric excitation cannot be reproduced well for the rolling bench test, the influences of the structural characteristics of the wheelset or bogie, wheelset lateral displacement and yaw angle (simulating vehicle curving), wheel-rail lubricant, etc., on the formation of the wheel polygonal wear can be elucidated.

(2) Experimental study of vibration behaviour of the wheelset. It has been reported that the formation of wheel polygonal wear of many types of vehicles is related to the lower bending and torsional vibration modes of the wheelset. It can be seen from the modal analysis of the wheelset that the wheel mainly vibrates in the lateral direction when the wheelset undergoes bending vibration. The lateral sliding between the wheel and the rail will lead to periodic fluctuations of the lateral creepage and creep force, thus forming polygonal wear of the wheel. The bending vibration of the wheelset, especially the second bending vibration, has a small deformation at the end of the wheelset axle. It is not easy to identify this bending vibration of the wheelset through an accelerometer installed on the axle box, but the deformation of the wheel is greater than that at the axle box. By using a telemetry device to measure the vibration behaviour of the wheel and axle, it is more conducive to study the mechanism of polygonal wear caused by the lower bending and torsional vibration modes of the wheelset.

(3) Research on the prediction model of wheel polygonal wear. The process shown in Fig. 19 is generally used for the prediction of wheel polygonal wear. However, for high-order polygonal wear, there is still a lot of work to be carried out in the simulation model: (1) Wheel-rail contact modelling under the mid-highfrequency excitation. The Hertz contact spring is generally used to solve the normal load in dynamic simulations. The accuracy of the Hertz spring under mid-high-frequency excitation is worth exploring. (2) Establishing the interaction model of the wheel and brake shoe or tread cleaner, and considering its effect on the repairing wheel roundness. (3) Elaboration of the vehicle-track coupled dynamics model. The flexibilities of vehicle and track components should be fully accounted for $[100,126,127]$. (4) Study on 
the phase relationship between external excitation, vehicle-track system coupling vibration, wheel-rail contact response, and wheel polygonal wear growth, and determining the cumulative rule and evolution process of wheel polygonal wear. (5) Considering the influence of work hardening of wheel surface material under wheel-rail rolling contact on wheel polygonal wear. (6) Experimental verification of the simulation model.

(4) Research on online monitoring technology of wheel polygonal wear. Currently, the measurement of the wheel OOR mainly depends on the wheel roughness measurement device or underfloor wheel lathe with a measurement function. Although this offline measurement method is highly accurate, its measurement efficiency is low, which is not conducive to monitoring of the development of wheel polygonal wear. Therefore, it is necessary to develop wheel polygonal wear test technology, based on the vehicle or wayside, that can provide technical support for vehicle condition maintenance and ensure the operational safety of railway vehicles.

(5) Development of maintenance criterion for wheel polygonal wear. Currently, the maintenance criterion of wheel polygonal wear is formulated by the vehicle operation department according to the operation experience in China, which lacks scientific verification. The impact of wheel polygonal wear on the vehicle-track system is closely related to the running speed of the vehicle, and the order and amplitude of wheel polygonal wear. These factors need to be considered. The influence of wheel polygonal wear on wheel-rail interaction, vehicle vibration, noise, and fatigue reliability of the vehicle and track components should be fully considered and a scientific and reasonable maintenance criterion should be formulated.

Acknowledgements An appreciation is given to Prof. Wanming Zhai of Southwest Jiaotong University for the suggestion on improving this article. Authors are grateful for sincere and valuable advices of referees and editor. This work is supported by the National Natural Science Foundation of China (Grant Nos. 51875484, U1734201, 51805450, 51775455, U1434201 and 51475390), the Science and Technology Program of Sichuan Province of China (Grant No. 2020YFQ0024), the Scientific Research Foundation of the State Key Laboratory of Traction Power of Southwest Jiaotong University (Grant Nos. 2020TPL-T03 and 2020TPL-T12), and China Postdoctoral Science Foundation (Grant No. 2020M673281).

Open Access This article is licensed under a Creative Commons Attribution 4.0 International License, which permits use, sharing, adaptation, distribution and reproduction in any medium or format, as long as you give appropriate credit to the original author(s) and the source, provide a link to the Creative Commons licence, and indicate if changes were made. The images or other third party material in this article are included in the article's Creative Commons licence, unless indicated otherwise in a credit line to the material. If material is not included in the article's Creative Commons licence and your intended use is not permitted by statutory regulation or exceeds the permitted use, you will need to obtain permission directly from the copyright holder. To view a copy of this licence, visit http://creativecommons. org/licenses/by/4.0/.

\section{References}

1. Knothe K, Grassie SL (1999) Workshop on rail corrugations and out-of-round wheels. J Sound Vib 227(5):895-897

2. Barke DW, Chiu WK (2005) A review of the effects of out-ofround wheels on track and vehicle components. Proc Inst Mech Eng Part F J Rail Rapid Trans 219(3):151-175

3. Nielsen JCO, Mirza A, Cervello S, Huber P, Müller R, Nelain B, Ruest P (2015) Reducing train-induced ground-borne vibration by vehicle design and maintenance. Int J Rail Transp 3(1):17-39

4. Nielsen JCO, Johansson A (2000) Out-of-round railway wheels-a literature survey. Proc Inst Mech Eng Part F J Rail Rapid Transit 214(2):79-91

5. Nielsen JCO, Lundén R, Johansson A, Vernersson T (2003) Train-track interaction and mechanisms of irregular wear on wheel and rail surfaces. Veh Syst Dyn 40(1-3):3-54

6. Zacher M (1990) Unrunde räder und oberbausteifigkeit. Eisenbahntechnische Rundschau 45(10):605-610

7. Pallgen G (1998) Unrunde räder an eisenbahnfahrzeugen. Eisenbahningenieur 49(1):56-60

8. Kalousek J, Johnson KL (1992) An investigation of short pitch wheel and rail corrugations on the Vancouver mass transit system. Proc Inst Mech Eng Part F J Rail Rapid Transit 206(2):127-135

9. Dings PC, Dittrich MG (1996) Roughness on Dutch railway wheels and rails. J Sound Vib 193(1):103-112

10. Johansson A (2006) Out-of-round railway wheels-assessment of wheel tread irregularities in train traffic. J Sound Vib 293(3-5):795-806

11. Nielsen JCO, Mirza A, Cervello S, Frid A, Müller R, Nélain B, Ruest P (2013) Train induced ground vibration-optimised rolling stock mitigation measures and their parameters. RIVAS (SCP0-GA-2010-265754) Deliv 5:4

12. Reitmann E, Fröhling RD, Hettasch G (2017) Identification and monitoring of polygonised railway wheels using existing wheel impact monitoring measurement data. In: Proceedings of the 11th international heavy haul association conference (IHHA 2017), Cape Town, South Africa, 2-6 September 2017, pp 826-833

13. Li L (2010) Influence of polygonal wheel of subway LIM train on dynamic behavior. Dissertation, Southwest Jiaotong Univesity, Chengdu (in Chinese)

14. Tao G, Wen Z, Liang X, Ren D, Jin X (2019) An investigation into the mechanism of the out-of-round wheels of metro train and its mitigation measures. Veh Syst Dyn 57(1):1-16

15. Yang X, Li W, Tao G, Wen Z (2020) The mechanism of highorder polygonal wear of metro train wheels. In: Klomp M, Bruzelius F, Nielsen J, Hillemyr A (eds) Advances in dynamics of vehicles on roads and tracks. IAVSD 2019. Lecture notes in mechanical engineering. Springer, Cham

16. Tao G, Xie C, Wang H, Yang X, Ding C, Wen Z (2020) An investigation into the mechanism of high-order polygonal wear of metro train wheels and its mitigation measures. Veh Syst Dyn. https://doi.org/10.1080/00423114.2020.1770810 
17. Li D, Dai H, Jia X, He B (2018) Out-of-round of subway wheel caused by rail flexibility. In: Proceedings of 11th international conference on contact mechanics and wear of rail/wheel system (CM2018), Delf, the Netherlands, 24-27 September 2018, pp 529-535

18. Tao G, Wang L, Wen Z, Guan Q, Jin X (2018) Measurement and assessment of out-of-round electric locomotive wheels. Proc Inst Mech Eng Part F J Rail Rapid Transit 232(1):275-287

19. Yang Y, Liang L, Liu P, Wang K, Zhai W (2020) Experimental investigation of essential feature of polygonal wear of locomotive wheels. Measurement 166(108199):1-12

20. Morys B (1999) Enlargement of out-of-round wheel profiles on high speed trains. J Sound Vib 227(5):965-978

21. Li L, Xiao X, Jin X (2011) Interaction of subway LIM vehicle with ballasted track in polygonal wheel wear development. Acta Mech Sin 27(2):297-307

22. Liu X, Zhai W (2014) Analysis of vertical dynamic wheel/rail interaction caused by polygonal wheels on high speed trains. Wear 314(1-2):282-290

23. Wu X, Rakheja S, Qu S, Wu P, Zeng J, Ahmed AKW (2018) Dynamic responses of a high speed railway car due to wheel polygonalisation. Veh Syst Dyn 56(12):1817-1837

24. Qu S, Wang J, Zhang D, Shi H, Wu P, Dai H (2018) Field investigation on the higher-order polygon wear on wheel of high speed trains. In: Proceedings of 11th International conference on contact mechanics and wear of rail/wheel system (CM2018), Delf, the Netherlands, 24-27 September 2018, pp 818-823

25. Han J, Zhong S, Xiao X, Wen Z, Zhao G, Jin X (2018) High speed wheel-rail contact determining method with rotating flexible wheelset and validation under wheel polygon excitation. Veh Syst Dyn 56(8):1233-1249

26. Zhong S, Xiong J, Xiao X, Wen Z, Jin X (2014) Effect of the first two wheelset bending modes on wheel-rail contact behavior. J Zhejiang Univ Sci A (Appl Phys Eng) 15(12):984-1001

27. Lan Q, Dhanasekar M, Handoko YA (2019) Wear damage of out-of-round wheels in rail wagons under braking. Eng Fail Anal 102:170-186

28. Zhang P, Zhao X, Ling L, Wen Z (2020) Influence of contact modeling on numerical analyses of high frequency wheel-rail interactions. J Mech Eng 56(12):124-132 (in Chinese)

29. Kou J (2018) Analysis on dynamic responses of polygonised wheel of high speed train using explicit FE method. Dissertation, Southwest Jiaotong Univesity, Chengdu (in Chinese)

30. Zhao X, Li Z (2011) The solution of frictional wheel-rail rolling contact with a $3 \mathrm{D}$ transient finite element model: Validation and error analysis. Wear 271(1-2):444-452

31. Liu K, Lin Jing (2019) A finite element analysis-based study on the dynamic wheel-rail contact behaviour caused by wheel polygonization. Proc Inst Mech Eng Part F J Rail Rapid Transit 234(10):1285-1298

32. Johansson A, Nielsen JCO (2003) Out-of-round railway wheels-wheel-rail contact forces and track response derived from field tests and numerical simulations. Proc Inst Mech Eng Part F J Rail Rapid Transit 217(2):135-146

33. Li X, Zeng Y, Li F, Tian G, Qin J (2019) Compound measuring zone method for continuous measurement of wheel/rai vertical force on ground. China Railw Sci 40(5):87-94 (in Chinese)

34. Tao G, Wen Z, Guan Q, Lu W, Fu Q, Jin X, Wang L (2016) Experimental investigation of the abnormal vibration of the electric locomotive. In: Proceedings of the 18th international wheelset congress (IWC 2016), Chengdu, pp 44-49

35. Wu P, Li G, Wu X, Zhang F (2017) Wheel polygonalizationinduced axle box vibrations and bolt self-loosening for high speed train. In: Proceedings of the 25th international symposium dynamics of vehicles on roads tracks (IAVSD 2017), vol 2.
Rockhampton, Queensland, Australia, 14-18 August 2017, pp 1191-1196

36. Wu X, Rakheja S, Wu H, Qu S, Wu P, Dai H, Zeng J, Ahmed AKW (2019) A study of polygonal wheel wear through a field test programme. Veh Syst Dyn 57(6):914-934

37. Cai W, Chi M, Wu X, Sun J, Zhou Y, Wen Z, Liang S (2020) A long-term tracking test of high-speed train with wheel polygonal wear. Veh Syst Dyn. https://doi.org/10.1080/00423114.2020. 1786592

38. Fayos J, Baeza L, Denia FD, Tarancón JE (2007) An Eulerian coordinate-based method for analysing the structural vibrations of a solid of revolution rotating about its main axis. J Sound Vib 306(3-5):618-635

39. Baeza L, Fayos J, Roda A, Insa R (2008) High frequency railway vehicle-track dynamics through flexible rotating wheelsets. Veh Syst Dyn 46(7):647-662

40. Torstensson PT, Nielsen JCO, Baeza L (2011) Dynamic traintrack interaction at high vehicle speeds-modelling of wheelset dynamics and wheel rotation. J Sound Vib 330(22):5309-5321

41. Martínez-Casas J, Fayos J, Denia FD, Baeza L (2012) Dynamics of damped rotating solids of revolution through an Eulerian modal approach. J Sound Vib 331(4):868-882

42. Wang J, Qu S, Li G, Wu P, Dai H (2017) Field test study on vibration transmission of high speed train with polygonised wheels. In: Proceedings of the 25th international symposium dynamics of vehicles on roads tracks (IAVSD 2017), vol 2. Rockhampton, Queensland, Australia, 14-18 August 2017, pp $1353-61358$

43. Lv K, Wang K, Chen Z, Cai C, Guo L (2017) Influence of wheel eccentricity on vertical vibration of suspended monorail vehicle: experiment and simulation. Shock Vib 1367683:1-10

44. Jiang Y, Wu P, Zeng J, Wei L, Lv L, Zhang Y, Dai X (2019) Detection and alleviation of the abnormal vibration of the monorail based on experiment and simulation. J Low Freq Noise Vib Active Control 38(2):282-295

45. Han Z, Chen Z, Zhai W (2017) Effect of wheel polygonal wear on dynamic responses of high speed train-track-bridge system. In: Proceedings of the 25th international symposium dynamics of vehicles on roads tracks (IAVSD 2017), vol 2. Rockhampton, Queensland, Australia, 14-18 August 2017, pp 823-828

46. Chen M, Sun Y, Guo Y, Zhai W (2019) Study on effect of wheel polygonal wear on high speed vehicle-track subgrade vertical interactions. Wear 432-433(102914):1-9

47. Mirza A, Frid A, Nielsen JCO (2013) Reduction of train induced ground vibration by vehicle design. In: Nielsen JCO, Anderson D, Gautier PE, Iida M, Nelson JT, Thompson D, Tielkes T, Towers DA, Paul de Vos (eds) Noise and vibration mitigation for rail transportation systems (IWRN 2013), Notes on numerical fluid mechanics and multidisciplinary design. Springer Heidelberg, pp 523-530

48. Huber PH, Nélain B, Müller R (2013) Experimental analysis of SBB ground vibration measurements and vehicle data. In: Nielsen JCO, Anderson D, Gautier PE, Iida M, Nelson JT, Thompson D, Tielkes T, Towers DA, Paul de Vos (eds) Noise and vibration mitigation for rail transportation systems (IWRN 2013), Notes on numerical fluid mechanics and multidisciplinary design. Springer Heidelberg, pp 531-538

49. Fang J, Xiao X, Lu L, Jin X (2010) Influence of subway LIM train wheel polygonisation on the vibration and sound radiation characteristics of it. In: Maeda T, Gautier PE, Hanson CE, Hemsworth B, Nelson JT, Schulte-Werning B, Thompson D, Paul de Vos (eds) Noise and vibration mitigation for rail transportation systems (IWRN 2010), Notes on numerical fluid mechanics and multidisciplinary design. Springer, Heidelberg, pp 117-124 
50. Zhang J, Xiao X, Han G, Deng Y, Jin X (2013) Study on abnormal interior noise of high-speed trains. In: Nielsen JCO, Anderson D, Gautier PE, Iida M, Nelson JT, Thompson D, Tielkes T, Towers DA, Paul de Vos (eds) Noise and vibration mitigation for rail transportation systems (IWRN 2013), Notes on numerical fluid mechanics and multidisciplinary design. Springer, Heidelberg, pp 691-698

51. Zhang J, Han G, Xiao X, Wang R, Zhao Y, Jin X (2014) Influence of wheel polygonal wear on interior noise of high speed trains. J Zhejiang Univ Sci A (Appl Phys Eng) 15(12):1002-1018

52. Han G, Zhang J, Xiao X, Cui D, Jin X (2014) Study on high speed train abnormal interior vibration and noise related to wheel roughness. J Mech Eng 50(22):113-121 (in Chinese)

53. Wu X, Chi M, Wu P (2015) Influence of polygonal wear of railway wheels on the wheel set axle stress. Veh Syst Dyn 53(11):1535-1554

54. Wu X, Chi M, Gao H (2016) Damage tolerances of a railway axle in the presence of wheel polygonalizations. Eng Fail Anal $66: 44-59$

55. Li G, Liu Z, Wang W, Yang G (2017) Fatigue crack mechanism study on high-speed EMU gearbox. J Mech Eng 53(2):99-105 (in Chinese)

56. Zhang B, Tan ACC, Lin J (2016) Gearbox fault diagnosis of high-speed railway train. Eng Fail Anal 66:407-420

57. Hu W, Liu Z, Liu D, Liu D, Hai X (2017) Fatigue failure analysis of high speed train gearbox housings. Eng Fail Anal 73:57-71

58. Yuan Y, Li Q, Yang G, Chang C (2016) Line test and abnormal vibration analysis of high-speed train gearbox. Railw Loco Car 36(1):24-29 (in Chinese)

59. Wu H, Wu P, Li F, Shi H, Xu K (2019) Fatigue analysis of the gearbox housing in high speed trains under wheel polygonisation using a multibody dynamics algorithm. Eng Fail Anal 100:351-364

60. Wang Z, Mei G, Zhang W, Cheng Y, Zou H, Huang G, Li F (2018) Effects of polygonal wear of wheels on the dynamic performance of the gearbox housing of a high speed train. Proc Inst Mech Eng Part F J Rail Rapid Transit 232(6):1852-1863

61. Wang Z, Cheng Y, Mei G, Zhang W, Huang G, Yin Z (2020) Torsional vibration analysis of the gear transmission system of high speed trains with wheel defects. Proc Inst Mech Eng Part F J Rail Rapid Transit 234(2):123-133

62. Wang Z, Allen P, Mei G, Yin Z, Cheng Y, Zhang W (2019) Dynamic characteristics of a high speed train gearbox in the vehicle-track coupled system excited by wheel defects. Proc Inst Mech Eng Part F J Rail Rapid Transit 234(10):1210-1224

63. Peng L, Han J, Chu D, Gao Y, Li Z, Xiao X (2019) Analysis of abnormal vibration characteristics and causes of vertical block in high-speed EMU. J Mech Eng 55(12):121-127 (in Chinese)

64. Wang W, Bai J, Wu S, Zheng J, Zhou P (2020) Experimental investigations on the effects of fatigue crack in urban metro welded bogie frame. Appl Sci 10(4):1-13

65. Xiao J, Hu H, Yan Z, Li W, Tu Y, Fang H (2018) The influence of wheel/rail vibration on the damage of rail fastening system of high speed railway in China. In: Proceedings of 11th international conference on contact mechanics and wear of rail/wheel system (CM2018), pp 1122-1127

66. CEN; EN 15313:2016. Railway applications-in-service wheelset operation requirements In-service and off-vehicle wheelset maintenance. British Standard Brussels

67. Rode W, Müller D, Villman J (1997) Results of DB AG investigations-out-of-round wheels. In: Proceedings corrugation symposium-extended abstracts, IFV Bahntechink, Technische Universität Berlin, Berlin, Germany
68. Meinke P, Meinke S (1999) Polygonalization of wheel treads caused by static and dynamic imbalances. J Sound Vib 227(5):979-986

69. Ren D, Tao G, Liu H, Liang H, Chen G, Wen Z (2019) Analysis of abnormal turning repair for locomotive wheels with polygonal wear and improvement measures. J Cntrl South Univ (Sci Tech) 50(9):2317-2326 (in Chinese)

70. Cui D, An B, Allen P, Wang R, Wang P, Wen Z, Li L (2019) Effect of the turning characteristics of underfloor wheel lathes on the evolution of wheel polygonisation. Proc Inst Mech Eng Part F J Rail Rapid Transit 233(5):479-488

71. Su J, Li L, Cui D (2017) Study on influence of turning repair operations on wheels with initial polygonal state. J China Railw Soc 39(5):57-61 (in Chinese)

72. Jenkins HH, Stephenson JE, Clayton GA, Morland GW, Lyon D (1974) The effect of track and vehicle parameters on wheel/rail vertical dynamics forces. Rail Eng J 3:2-16

73. Grassie GL (2009) Rail corrugation: characteristics, causes, and treatments. Proc Inst Mech Eng Part F J Rail Rapid Transit 223(6):581-596

74. Johansson A, Andersson C (2005) Out-of-round railway wheels - a study of wheel polygonalization through simulation of three-dimensional wheel-rail interaction and wear. Veh Syst Dyn 43(8):539-559

75. Cai W, Chi M, Tao G, Wu X, Wen Z (2019) Experimental and numerical investigation into the formation of metro wheel polygonalization. Shock Vib 2019:1-18

76. Chen G, Jin X, Wu P, Dai H, Zhou Z (2011) Finite element study on the generation mechanism of polygonal wear of railway wheels. J China Railw Soc 33(1):14-18 (in Chinese)

77. Chen G, Cui X, Wang K (2016) Generation mechanism for plolygonalization of wheel treads of high-speed trains. J Southw Jiaotong Univ 51(2):243-250 (in Chinese)

78. Zhao XN, Chen GX, Lv JZ, Zhang S, Wu BW, Zhu Q (2019) Study on the mechanism for the wheel polygonal wear of high speed trains in terms of the frictional self-excited vibration theory. Wear 426-427:1820-1827

79. Wu BW, Qiao QF, Chen GX, Lv JZ, Zhu Q, Zhao XN, Ouyang $\mathrm{H}$ (2020) Effect of the unstable vibration of the disc brake system of high speed trains on wheel polygonalization. Proc Inst Mech Eng Part F J Rail Rapid Transit 234(1):80-95

80. Jin X, Wu L, Fang J, Zhong S, Liang L (2012) An investigation into the mechanism of the polygonal wear of metro train wheels and its effect on the dynamic behaviour of a wheel/rail system. Veh Syst Dyn 50(12):1817-1834

81. Tao G, Wang L, Wen Z, Guan Q, Jin X (2018) Experimental investigation into the mechanism of the polygonal wear of electric locomotive wheels. Veh Syst Dyn 56(6):883-899

82. Tao G, Liu X, Wen Z, Jin X (2020) On the formation process, key influencing factors and countermeasures of high-order polygonal wear of locomotive wheels. J Zhejiang Univ Sci A (Appl Phys Eng). https://doi.org/10.1631/jzus.A2000081

83. Tao G, Wen Z, Chen G, Yun L, Jin X (2020) Locomotive wheel polygonisation due to discrete irregularities: simulation and mechanism. Veh Syst Dyn. https://doi.org/10.1080/00423114. 2020.1737148

84. Fröhling R, Spangenberg U, Reitmann E (2019) Root cause analysis of locomotive wheel tread polygonisation. Wear 432-433(102911):1-12

85. Spangenberg U (2020) Variable frequency drive harmonics and interharmonics exciting axle torsional vibration resulting in railway wheel polygonisation. Veh Syst Dyn 58(3):404-424

86. Wu X, Rakheja S, Cai W, Chi M, Ahmed AKW, Qu S (2019) A study of formation of high order wheel polygonalization. Wear 424-425:1-14 
87. Cai W, Chi M, Wu X, Li F, Wen Z, Liang S, Jin X (2019) Experimental and numerical analysis of the polygonal wear of high-speed trains. Wear 440-441(203079):1-12

88. Dai H, Li D, Wang J, Qu S (2018) Study on the mechanism of high order out of round roughness of high speed railway train's wheel. In: Proceedings of 11th international conference on contact mechanics and wear of rail/wheel system (CM2018), pp 189-195

89. Qu S, Zhu B, Zeng J, Dai H, Wu P (2020) Experimental investigation for wheel polygonisation of high-speed trains. Veh Syst Dyn. https://doi.org/10.1080/00423114.2020.1772984

90. Wu Y, Du X, Zhang H, Wen Z, Jin X (2017) Experimental analysis of the mechanism of high-order polygonal wear of wheels of a high speed train. J Zhejiang Univ Sci A (Appl Phys Eng) 18(8):579-592

91. Guo T, Gao F, Zhang X, Han Y, Hou M (2019) Experimental study on polygon wear of wheel tread on high speed train. Railw Loco Car 39(1):64-67 (in Chinese)

92. Ma W, Song R, Luo S (2016) Study on the mechanism of the formation of polygon-shaped wheels on subway vehicles. Proc Inst Mech Eng Part F J Rail Rapid Transit 230(1):129-137

93. Liu W, Zong L, Luo S, He X (2016) Research into the problem of wear creating a polygon-shaped wheel on metro trains. Proc Inst Mech Eng Part F J Rail Rapid Transit 230(1):43-55

94. Fu B, Bruni S, Luo S (2019) Study on wheel polygonisation of a metro vehicle based on polygonal wear simulation. Wear 438-439(203071):1-14

95. Vernersson T (1999) Thermally induced roughness of tread braked railway wheels, Part 1: brake rig experiments. Wear 236(1-2):96-105

96. Vernersson T (1999) Thermally induced roughness of tread braked railway wheels, Part 2: modelling and field measurements. Wear 236(1-2):106-116

97. Soua B, Pascal JP (1995) Computation of the 3D wear of the wheels in a high speed bogie. Report INRETS-LTN, Arcueil, France, pp 21-40

98. Brommundt E (1997) A simple mechanism for the polygonalization of railway wheels by wear. Mech Res Commun 24(2):435-442

99. Meywerk M (1999) Polygonalization of railway wheels. Arch Appl Mech 69:105-120

100. Zhai W (2020) Vehicle-track coupled dynamics theory and applications. Springer, Singapore

101. Peng B, Iwnicki S, Shackleton P, Crosbee D, Zhao Y (2019) The influence of wheelset flexibility on polygonal wear of locomotive wheels. Wear 432-433(102917):1-11

102. Peng B, Iwnicki S, Shackleton P, Crosbee D (2019) Comparison of wear models for simulation of railway wheel polygonisation. Wear 436-437(203010):1-13

103. Peng B, Iwnicki S, Shackleton P, Song Y (2020) General conditions for railway wheel polygonal wear to evolve. Veh Syst Dyn. https://doi.org/10.1080/00423114.2019.1697458

104. Ye Y, Shi D, Krause P, Tian Q, Hecht M (2019) Wheel flat can cause or exacerbate wheel polygonisation. Veh Syst Dyn 58(10):1575-1604

105. Pearce TG, Sherratt ND (1991) Prediction of wheel profile wear. Wear 144:343-351

106. Jendel T (2002) Prediction of wheel profile wear-comparisons with field measurements. Wear 253(1-2):89-99

107. Lewis R, Dwyer-Joyce RS (2004) Wear mechanisms and transitions in railway wheel steels. Proc Inst Mech Eng Part F J Rail Rapid Transit 218(6):467-478

108. Zobory I (1997) Prediction of wheel/rail profile wear. Veh Syst Dyn 28(2-3):221-259
109. Spiryagin M, Polach O, Cole C (2013) Creep force modelling for rail traction vehicles based on the Fastsim algorithm. Veh Syst Dyn 51(11):1765-1783

110. Knothe K, Groß-thebing A (2008) Short wavelength rail corrugation and non-steady-state contact mechanics. Veh Syst Dyn 46(1-2):49-66

111. Baeza L, Vila P, Xie G, Iwnicki SD (2011) Prediction of rail corrugation using a rotating flexible wheelset coupled with a flexible track model and a non-Hertzian/non-steady contact model. J Sound Vib 330(18-19):4493-4507

112. Vila P, Baeza L, Martínez-Casas J, Carballeira J (2014) Rail corrugation growth accounting for the flexibility and rotation of the wheel set and the non-Hertzian and non-steady-state effects at contact patch. Veh Syst Dyn 52: 92-108

113. Torstensson PT, Pieringer A, Nielsen JCO (2014) Simulation of rail roughness growth on small radius curves using a nonHertzian and non-steady wheel-rail contact model. Wear 314(1-2):241-253

114. Li G, Chang C, Chen B, Wang J (2018) Test and research on eliminating polygon phenomenon of wheels with abrasive block of tread cleaner. Roll Stock 56(5):4-6 (in Chinese)

115. Li G, Liu T, Han Q, Song C, Han G, Li X (2019) Research on test and application of modifier for wheel treads of high-speed multiple units. Railw Veh 57(12):6-8 (in Chinese)

116. Qiao Q, Li M, Zhao X, Chen G (2020) Study on the mechanism of the abrasive block suppressing wheel polygonal wear of highspeed trains. Tribology 40(2):234-239 (in Chinese)

117. Mädler K, Bettac H, Geidel D, Müller D, Okagata Y (2012) Wheel steels for solving wheel out-of-roundness problems on high-speed trains in Germany. In: Proceedings of 9th international conference on contact mechanics and wear of rail/wheel system (CM2012), Chengdu, China, 27 August 2012, pp $188-189$

118. Chang C, Li G, Zhang Y, Zhou S (2018) Experimental study on influence of wheel-rail material hardness matching on wheel polygonal wear. China Railw Sci 39(2):87-93 (in Chinese)

119. Shen W, Song C, Li G, Li X, Li Cui (2018) Research on highspeed EMU wheel hardness and polygon-form relationships with solutions. Railw Loco Car 38(4):18-23 (in Chinese)

120. Song C, Shen W, Li X, Cui L (2017) On the influencing factors and inhibiting measures of wheel polygons of high-speed EMUs. China Railw 11:33-40 (in Chinese)

121. Heyder R, Maedler K (2015) The influence of wheel and rail material on the wear of the respective contact partner. In: Proceedings of 10th International conference on contact mechanics and wear of rail/wheel system (CM2015), pp 1-3

122. Qian Q (2019) Study on wheel polygon comprehensive improvement of Wuguang high-speed line. Railw Loco Car 39(2):50-54 (in Chinese)

123. Spangenberg U, Fröhling RD (2020) Solving locomotive wheel polygonisation by reducing variable frequency drive interharmonics. Proc Inst Mech Eng Part F J Rail Rapid Transit. https:// doi.org/10.1177/0954409720904279

124. Pan R, Zhao X, Liu P, Ren R (2017) Micro-mechanism of polygonization wear on railroad wheels. Wear 392-393:213-220

125. Hua J, Zhao X, Liu P, Pan J, Su C, Ren R (2020) Study on the mechanism for polygonisation formation of $\mathrm{D} 2$ wheel steel and its effect on microstructure and properties under rolling wear conditions. Wear 450-451(450451):1-12

126. Zhai W, Wang K, Cai C (2009) Fundamentals of vehicle-track coupled dynamics. Veh Syst Dyn 47(11):1349-1376

127. Zhai W, Han Z, Chen Z, Li Ling, Zhu S (2019) Train-trackbridge dynamic interaction: a state-of-the-art review. Veh Syst Dyn 57(7):984-1027 